University of Wollongong

Research Online

Faculty of Engineering and Information

Faculty of Engineering and Information

Sciences - Papers: Part A

Sciences

$1-1-2017$

\title{
Axial load-bending moment diagrams of GFRP reinforced columns and GFRP encased square columns
}

Jim Youssef

University of Wollongong, jy201@uowmail.edu.au

Muhammad N. S Hadi

University of Wollongong, mhadi@uow.edu.au

Follow this and additional works at: https://ro.uow.edu.au/eispapers

Part of the Engineering Commons, and the Science and Technology Studies Commons

Research Online is the open access institutional repository for the University of Wollongong. For further information contact the UOW Library: research-pubs@uow.edu.au 


\title{
Axial load-bending moment diagrams of GFRP reinforced columns and GFRP encased square columns
}

\begin{abstract}
Fiber reinforced polymer (FRP) pultruded materials are available in a wide variety of shapes, including bars, I-sections, C-sections and other structural sections. Due to their high durability, low self-weight and reduced maintenance costs, these FRP materials are becoming a competitive option for replacing steel as structural materials especially in corrosive environments. This paper summarizes an experimental program on the axial and flexural behaviour of square concrete members reinforced with glass fiber reinforced polymer (GFRP) bars and embedded with pultruded GFRP structural sections under different loading conditions. Furthermore, an analytical model is presented to predict the axial load-bending moment interaction diagrams of the experimentally tested specimens. It can be concluded from this study that the analytical models provide reliable estimates of the maximum load and bending moment capacities of GFRP reinforced and GFRP encased concrete columns. In addition, a parametric study was conducted to study the effects of concrete compressive strength and longitudinal GFRP reinforcement ratio on the structural performance of GFRP reinforced square concrete columns.
\end{abstract}

\section{Keywords}

square, columns, reinforced, gfrp, diagrams, moment, load-bending, axial, encased

\section{Disciplines}

Engineering | Science and Technology Studies

\section{Publication Details}

Youssef, J. \& Hadi, M. N. S. (2017). Axial load-bending moment diagrams of GFRP reinforced columns and GFRP encased square columns. Construction and Building Materials, 135 550-564. 

GFRP Encased Square Columns

\author{
Jim Youssef ${ }^{1}$ and Muhammad N.S. Hadi ${ }^{2}$
}

\title{
4 Abstract
}

5 Fiber reinforced polymer (FRP) pultruded materials are available in a wide variety of shapes,

6 including bars, I-sections, C-sections and other structural sections. Due to their high

7 durability, low self-weight and reduced maintenance costs, these FRP materials are becoming

8 a competitive option for replacing steel as structural materials especially in corrosive

9 environments. This paper summarizes an experimental program on the axial and flexural

10 behaviour of square concrete members reinforced with glass fiber reinforced polymer

11 (GFRP) bars and embedded with pultruded GFRP structural sections under different loading

12 conditions. Furthermore, an analytical model is presented to predict the axial load-bending

13 moment interaction diagrams of the experimentally tested specimens. It can be concluded

14 from this study that the analytical models provide reliable estimates of the maximum load and

15 bending moment capacities of GFRP reinforced and GFRP encased concrete columns. In

16 addition, a parametric study was conducted to study the effects of concrete compressive

17 strength and longitudinal GFRP reinforcement ratio on the structural performance of GFRP

18 reinforced square concrete columns.

19 Keywords: Square Concrete Columns; GFRP Reinforcement; Application of FRPs; Hybrid structures; Pultruded shapes; P-M Interaction Diagram

\footnotetext{
${ }^{1}$ Ph.D. Candidate, School of Civil, Mining and Environmental Engineering, University of Wollongong, Wollongong, NSW 2522, Australia. Email: jy201@uowmail.edu.au

${ }^{2}$ Associate Professor, School of Civil, Mining and Environmental Engineering, University of Wollongong, Wollongong, NSW 2522, Australia. Email: mhadi@uow.edu.au, *Corresponding Author
} 


\subsection{Introduction}

22 The use of reinforcement with FRP composite materials have emerged as one of the

23 alternatives to steel reinforcement for concrete structures prone to corrosion issues. Currently,

24 design standards have been developed for FRP reinforced flexural members, including ACI

$25440.1 \mathrm{R}-15$ [1]. On the other hand, the level of understanding of the behaviour of FRP

26 reinforced compression members has not reached a level where design standards are available

27 for such members. Having said this, the current ACI 440.1R - 15 [1] design guideline mentions to neglect the compressive contribution of FRP reinforcement when used as reinforcement in columns, in compression members, or as compression reinforcement in

30 flexural members. Therefore, the acceptance of FRP by designers requires the development of design guidelines for the design of FRP bars in compression members such as columns. In this regard, limited experimental and analytical studies have been conducted to understand the compressive behaviour and failure modes of concrete columns internally reinforced with FRP and subjected to different loading conditions as discussed herein.

Kawaguchi [2] conducted an experimental study of twelve concrete specimens reinforced with aramid fiber-reinforced polymer (AFRP) bars. The specimens were tested in eccentric compression or tension. This study reported that the AFRP reinforced columns can be analysed using the same approach undertaken for concrete columns reinforced with steel bars. Choo et al. [3] reported that unlike steel reinforced columns, FRP reinforced columns interaction diagrams do not experience balance points due to the linear elastic material properties of the FRP bars until failure. Furthermore, FRP reinforced columns have a tendency to exhibit a failure point before the strength interaction reaches a pure bending condition, which is classified as brittle-tension failure due to the tensile rupture of the FRP

44 bars. They reported that this failure occurs when low reinforcement ratios are considered. 
pure bending, to calculate the minimum FRP reinforcement ratio to prevent the tensile failure of the FRP bars in the tension side. Zadeh and Nanni [5] developed interaction diagrams for GFRP reinforced columns subjected to combined flexural and axial loads by assuming the GFRP longitudinal bars are only effective in tension. Therefore, compression GFRP bars were replaced by an equivalent area of concrete. Furthermore, the authors suggested imposing a limit of $1 \%$ on the maximum design tensile strain of GFRP longitudinal bars in order to avoid exaggerated deflections. In another study, Hadi et al. [6] tested circular concrete columns reinforced with GFRP bars and helices under concentric and eccentric loading conditions. The load carrying and bending moment capacities of the GFRP reinforced specimens were calculated analytically with the same principles used for conventional steel reinforced specimens and were compared with the experimental results.

The alternative use of FRP structural profiles and tubes in concrete members presents a very interesting potential, either for rehabilitation of existing structures or for new construction due to their many advantages including low self-weight, ease of installation, low maintenance costs and corrosion resistance. However, FRP profiles generally have low in-plane moduli and wall slenderness making them particularly vulnerable to local buckling. Tomblin and Barbero [7] reported that the strength of short columns made of GFRP I-sections are governed by local buckling, while Zureick and Scott [8] concluded that the failure mechanism of long columns is by global buckling. There have been several studies aimed to examine the structural advantages of connecting GFRP pultruded profiles to concrete compression and flexural elements to make better use of the profiles [9.10]. However, the encasement of GFRP structural sections in concrete columns has only been studied by Hadi and Youssef [11].

This study is a continuation of the experimental study of Hadi and Youssef [11] in which an experimental program investigating the behaviour of GFRP reinforced and GFRP encased 
concrete columns and beams was presented. Parameters investigated included the magnitude of load eccentricity and type of internal reinforcement with steel reinforced, GFRP reinforced, GFRP I-section encased and GFRP C-sections encased concrete specimens tested under compressive and flexural loading. This paper presents an analytical model to predict the load-interaction diagrams of GFRP reinforced and GFRP encased square concrete specimens and attempts to theoretically validate the experimental results of Hadi and Youssef [11].

\subsection{Experimental Program}

\subsection{Design of Specimens}

80 The experimental component of this study involved testing four groups of four square 81 reinforced concrete columns under concentric as well as combined axial and flexural loading.

82 The first group of specimens were reinforced with steel bars (Group RS) and the second

83 group of specimens were reinforced with GFRP bars (Group RF). The first two groups of 84 specimens were designed to have similar longitudinal and transverse reinforcement ratios.

85 The longitudinal reinforcement ratio of the Group RS and Group RF specimens were 1.03 and $1.15 \%$, respectively. The third (Group I) and fourth group (Group C) of specimens were encased with a pultruded GFRP I-section and C-sections, respectively. Each specimen had a square cross section with a side dimension of $210 \mathrm{~mm}$ and a height of $800 \mathrm{~mm}$. The reinforcement details of all the groups of specimens are shown in Figure 1. Each group

90 consisted of four specimens; one specimen was tested concentrically, one tested under $25 \mathrm{~mm}$

91 eccentricity, one tested under $50 \mathrm{~mm}$ eccentricity and the last specimen was tested as a beam under four point loading test. The specimens are identified by the type of internal

93 reinforcement and magnitude of load eccentricity. For example, Specimen RS-25 is 
94 reinforced with steel bars and is eccentrically loaded at $25 \mathrm{~mm}$ from the centreline. The letter "B" denotes a beam specimen tested under flexural loading.

96 A detailed discussion of the design, preparation, testing and instrumentation of the specimens

97 is discussed in Hadi and Youssef [11].

\subsection{Preliminary Testing}

In this study, all the concrete specimens were cast on the same day. The average compressive strength of the concrete $\left(f_{c}^{\prime}\right)$ at 28 days was determined to be $29.3 \mathrm{MPa}$. Furthermore, the average compressive strength of concrete at the first day and last day of testing the specimens was $31 \mathrm{MPa}$ and $35.3 \mathrm{MPa}$, respectively. The compressive strengths were obtained by testing cylinders having a diameter of $100 \mathrm{~mm}$ and height of $200 \mathrm{~mm}$, with five cylinders tested for each the 28 day and last day of testing and three cylinders tested on the first day of testing to obtain an average value for each day of testing.

Deformed steel N12 bars were used as longitudinal reinforcement in Group RS specimens. Five samples were tested in accordance with AS 1391- 2007 [12] to determine the tensile properties of the reinforcing steel bars. The average yield stress $\left(f_{s y}\right)$, yield strain $\left(\varepsilon_{s y}\right)$ and modulus of elasticity $\left(E_{s}\right)$ were determined to be $540 \mathrm{MPa}, 0.324 \%$ and $200 \mathrm{GPa}$, respectively. Sand coated No. 4 (\#4) GFRP bars of $12.7 \mathrm{~mm}$ standard diameter were used to reinforce the Group RF specimens longitudinally. The GFRP bars were manufactured by Pultrall Inc. [13]. Five samples were tested in accordance with ASTM D7205-11 [14] to determine the tensile properties of the GFRP bars. The ultimate tensile stress, corresponding rupture strain and tensile modulus of elasticity were $1641 \mathrm{MPa}, 2.41 \%$ and $67.9 \mathrm{GPa}$, respectively. These properties were calculated based on the bar's standard diameter of 12.7 mm which was provided by the manufacturer [13]. 
117 GFRP pultruded I-sections and C-sections were used in the specimens of Group I and C, 118 respectively and they were supplied by GRP Australia [15]. The tensile properties of the

119 GFRP pultruded sections were determined based on the test method ISO 527-4-1997 [16] and

120 are shown in Table 1. Five coupon samples from each GFRP C-section, web of the I-section

121 and flange of the I-section were extracted in the longitudinal direction using a wet saw

122 machine. The coupons had nominal dimensions of $300 \mathrm{~mm}$ long and $25 \mathrm{~mm}$ wide and were

123 tested using a screw-driven material testing machine known as the $500 \mathrm{kN}$ Instron 8033

124 machine. The compressive properties of the GFRP pultruded sections were determined based

125 on the test method of ASTM D695-15 [17], as shown in Table 1. A total of 17 coupon

126 samples from each web of the GFRP C-section, web of the I-section and flange of the I-

127 section with nominal dimensions of $9.5 \times 12.7 \times 37.6 \mathrm{~mm}$ were extracted in the longitudinal

128 direction using a wet saw machine from the sections. To compensate for levelling errors,

129 either the top and bottom ends of the coupons were levelled with a mill and/or the coupons

130 were placed on a spherical seat. The coupons were tested under compression by direct end

131 loading using the Instron 8033 machine, as shown in Figure 2. Nine samples from the C-

132 section and eight samples each from the web and flange of the I-section were instrumented

133 with strain gauges to measure the elastic modulus in compression.

134 It can be concluded from the compression testing of the GFRP sections that there was a high

135 dispersion in the results [11]. Most notably the coefficients of variation (COV) for the

136 longitudinal compressive strength for the I-section and C-section were 15.5 and $26.9 \%$,

137 respectively. This dispersion in results may be the result of different issues such as premature

138 failures due to geometric instabilities or local end crushing, poor quality control at the

139 manufacturing level, the intrinsic nature of the test setup or due to the non-uniform placement

140 of the fibers throughout the cross section. It should be noted that it has been reported that the

141 compression testing of pultruded samples is difficult due to the high longitudinal strength and 
142 low transverse strength of the material [18]. As a result, the ends of most of the coupons

143 failed by either crushing or brooming. Therefore, the property measured may not be the

144 actual compressive strength but represent the composite bearing strength [18]. In addition,

145 from material testing it can be seen that the two shapes of GFRP sections varied in tensile and

146 compressive properties. The web of the I-section also had slightly lower tensile and

147 compressive strength and modulus as compared to the flange, as shown in Table 1.

\section{$148 \quad 3.0$ Experimental Results}

149 A detailed discussion of the strength, failure modes, failure locations and ductility of each

150 group of specimens under different types of eccentric loading were analysed and addressed in

151 Hadi and Youssef [11]. The following outlines the general behaviour and results of the tested

152 column and beam specimens. The summary of the specimen testing results is shown in Table

153 2. For the eccentrically loaded column specimens $(25 \mathrm{~mm}$ and $50 \mathrm{~mm})$, the bending moment

154 capacities $\left(M_{\exp }\right)$ corresponding to the first maximum axial load $\left(P_{\max }\right)$ was calculated by Eq.

155 (1). It should be noted that $P_{\max }$ corresponds to the first maximum load before the total onset

156 of concrete spalling after the initial linear region of the axial load - displacement curves.

157 When calculating the bending moments, both the application of the load at an eccentricity $(e)$

158 and secondary moments arising from the lateral deflection of the column at $P_{\max }(\delta)$ were

159 taken into account. For the beam specimens loaded under four-point loading, the bending

160 moment capacity was calculated by Eq. (2). This equation was obtained from simple statics

161 as the bending moment value between the two point loads as equalling half the maximum

162 applied load on the beam specimens multiplied by the shear span length $(a=235 \mathrm{~mm}$ in this

163 study).

164 The effects of eccentricity on the structural behaviour of the column specimens are shown in

165 Figure 3 . For all the groups of specimens, there was a reduction in the axial load carrying 
166 capacity with an increase in load eccentricity. Furthermore, the GFRP encased specimens

167 failed at lower axial displacements as compared to the other specimens.

$$
\begin{gathered}
M_{\text {exp }}=P_{\text {max }}(e+\delta) \\
M_{\text {exp }}=\frac{P_{\text {max }}}{2} a
\end{gathered}
$$

168 Strain gauges were also bonded on the internal longitudinal reinforcements and imbedded 169 sections. The location of the attached strain gauges is shown in Figure 1. For each 170 concentrically loaded specimen, two strain gauges were bonded to the longitudinal 171 reinforcement and imbedded sections at mid-height. Similarly, for the eccentrically loaded 172 specimens, two strain gauges were bonded on to the longitudinal bars, with one strain gauge 173 on the compression side and one on the tension side. For the imbedded GFRP I-sections, the 174 strain gauges were bonded in the middle of the two outside flanges at the mid-height. Only one GFRP C-section per specimen was instrumented with strain gauges which were located on the two flanges at mid-height, as shown in Figure 1.

177 At the first maximum load the average axial strain in the bars and GFRP sections for Specimens RS-0, RF-0, I-0 and C-0 ranged between 0.35 to $0.40 \%$. At this point the steel had reached its yield point and the axial strain for the GFRP bars in Specimen RF-0 was $14.7 \%$ of

180 the ultimate tensile rupture strain. Similarly, for all the eccentrically loaded specimens the

181 strains in the instrumented compression reinforcement and sections ranged between 0.35 to

$1820.40 \%$ at the first maximum load. On the other hand, the strain in the reinforcement located in 183 the tensile zone of the eccentrically loaded specimens varied. At maximum load, the steel bar 184 in the tension zone was still under slight compression for Specimen RS-25, while the 185 instrumented reinforcement and sections for Specimens RF-25, I-25 and C-25 were under 186 slight tension with values ranging from $0.01 \%$ to $0.06 \%$. However, the tensile reinforcement 
and sections for the specimens loaded under $50 \mathrm{~mm}$ eccentric load were exposed to higher tensile strains at maximum load with values ranging from $0.08 \%$ to $0.19 \%$. As mentioned above for the eccentrically loaded specimens only one strain gauge was placed on the tension and compression longitudinal bars and sections and no average could be obtained for each.

\section{$191 \quad$ 4.0 Analytical Modelling}

\subsection{Theoretical Considerations of Material Properties}

193 This section describes the stress-strain relationship of the constituent materials used in this 194 study. These materials include the concrete, steel reinforcement and GFRP reinforcement.

195 The relationships and the experimental material properties are used to theoretically calculate

196 the prediction of the bending moment and corresponding load carrying capacities of the 197 eccentrically loaded concrete specimens.

\subsubsection{Concrete}

199 The stress-strain model proposed by Yang et al. [19] was used to develop the compressive stress of the unconfined concrete in terms of the strains as follows:

$$
f_{c}=\left[\frac{\left(\beta_{1}+1\right)\left(\frac{\varepsilon_{c}}{\varepsilon_{c o}}\right)}{\left(\frac{\varepsilon_{c}}{\varepsilon_{c o}}\right)^{\beta_{1}+1}+\beta_{1}}\right] f_{c o}
$$

201 where $f_{c}$ is the compressive stress corresponding to the compressive strain $\varepsilon_{c} ; f_{c o}$ is the 202 unconfined concrete strength which is equal to $85 \%$ of the compressive cylinder strength of 203 concrete at the first day of testing; $\varepsilon_{c o}$ is the strain corresponding to $f_{c o}$; and $\beta_{1}$ is a 204 parameter that determines the slopes of the ascending and descending branches as illustrated below. It should be noted that a factor of $85 \%$ of the compressive cylinder strength of concrete is used in this study in order to take into account the size effect of the large concrete 
specimens as compared to the small cylinders used to develop the stress-strain model. A

208 factor of $90 \%$ has also been investigated in the analysis as shown below in the later sections.

209 The parameter $\beta_{1}$ controls the slope of the ascending and descending branch of the stress-

210 strain relationship, with Eq. (4) is used for the ascending branch and Eq. (5) is used for the

211 descending branch.

$$
\begin{gathered}
\beta_{1}=0.2 \exp (0.73 \xi) \text { for } \varepsilon_{c} \leq \varepsilon_{0} \\
\beta_{1}=0.41 \exp (0.77 \xi) \text { for } \varepsilon_{c}>\varepsilon_{0} \\
\xi=\left(\frac{f_{c o}}{f_{0}}\right)^{0.67}\left(\frac{w_{0}}{w_{c}}\right)^{1.17}
\end{gathered}
$$

212 where $f_{o}$ and $w_{o}$ are reference values equal to $10 \mathrm{MPa}$ and $2300 \mathrm{~kg} / \mathrm{m}^{3}$, respectively; and $\mathrm{w}_{\mathrm{c}}$ is

213 the concrete density assumed to be $2400 \mathrm{~kg} / \mathrm{m}^{3}$ for normal-weight concrete.

214 The modulus of elasticity $\left(E_{c}\right)$ is calculated using Eq. (7) as proposed in AS3600 - 2009 [20]

215 for concrete strengths less than $40 \mathrm{MPa}$. The unconfined concrete strain $\left(\varepsilon_{c o}\right)$ corresponding 216 to $f_{c o}$ is calculated using Eq. (8) as proposed by Yang et al. [19].

$$
\begin{gathered}
E_{c}=\left(0.043 \sqrt{f_{c o}}\right)\left(w_{c}\right)^{1.5} \\
\varepsilon_{c o}=0.0016 \exp \left[240\left(\frac{f_{c o}}{E_{c}}\right)\right]
\end{gathered}
$$

217 As noted above, the average compressive strength of concrete at 28 days, the first day and

218 last day of testing the specimens was 29.3, $31 \mathrm{MPa}$ and $35.3 \mathrm{MPa}$ respectively. Therefore,

219 herein the strength of each specimen in the analytical model was calculated using the concrete compressive strength at the first day of testing of $31 \mathrm{MPa}$. 


\subsubsection{Steel Longitudinal Bars}

222

223

224

225

226

227 follows:

$$
f_{S}=\varepsilon_{S} E_{S}
$$

where $f_{s}$ is the tensile stress and $E_{s}$ is the modulus of elasticity of the steel reinforcements.

On the other hand, in the post yield stage, the steel reinforcement reaches yield such that the stress is equal to the yield tensile stress $\left(f_{s y}\right)$, as follows:

$$
f_{s}=f_{s y}
$$

231

\subsubsection{GFRP Longitudinal Bars}

The GFRP reinforcing bars behave in a linear brittle manner up to failure when loaded in tension. In this study, the actual stress-strain response of the GFRP bars obtained by tensile testing illustrates the idealised linear elastic behaviour, as shown in Figure 5.

When loaded in compression, the behaviour of FRP bars is influenced by different modes of failure including transverse tensile failure, fiber microbuckling, or shear failure [1]. Therefore, there is no standard axial compression test method for FRP composites. However, the behaviour of FRP bars in compression needs to be established to allow for the design of FRP reinforced concrete columns. It has been reported that the compressive strengths of FRP bars are relatively low compared to the tensile strengths. In early studies, the compressive strengths of GFRP bars were reported to be $55 \%$ of the tensile strengths, while the compressive modulus of elasticity were $80 \%$ of the tensile modulus of elasticity [21-23]. 
243 Chaallal and Benmokrane [24] showed that the compressive strength of GFRP rods were

$24477 \%$ of the tensile strength. Kobayashi and Fujisaki [25] found that the compressive

245 strengths of the GFRP bars were 30 to $40 \%$ of their tensile strengths. Deitz et al. [26]

246 reported that the ultimate compressive strength is approximately equal to $50 \%$ of the ultimate

247 tensile strength, whereas there was no difference in the modulus of elasticity in compression

248 compared to that in tension. These studies indicate the test data of compression testing of

249 GFRP bars are widely scattered and subjected to significant variations, unlike the tensile

250 properties. Taking this into account, the compressive properties used in the analytical study

251 are explained in the sections below.

252 Considering the linear brittle behaviour of GFRP bars, the tensile stress in each bar can be

253 calculated using Hooke's Law, as follows:

$$
f_{f t}=\varepsilon_{f t} E_{f t}
$$

254 where $f_{f t}$ is the tensile stress and $E_{f t}$ is the tensile modulus of GFRP longitudinal 255 reinforcements.

256 Similarly, the compressive stress in each bar can be calculated using Hooke's Law, as 257 follows:

$$
f_{f c}=\varepsilon_{f c} E_{f c}
$$

258 where $E_{f c}$ is the compressive modulus of GFRP longitudinal reinforcements.

\subsubsection{GFRP Pultruded Sections}

260 GFRP pultruded sections are orthotropic materials with the fibers laid mainly in the

261 longitudinal direction. Therefore, these sections are stronger in the longitudinal direction as compared with the transverse direction. The sections are usually too narrow in the transverse direction to enable the extraction of standard coupons with dimensions as specified by the test

264 standards. Therefore, the transverse tensile properties of the pultruded structural sections 
265 could not be determined. Furthermore, considering the loads on columns are in the 266 longitudinal direction, only the longitudinal properties will be used in the analytical study.

267 Similar to GFRP bars the GFRP pultruded sections are linear elastic materials in both tension 268 and compression. Therefore, the tensile and compressive stresses can be calculated from 269 Hooke's Law similar to that of Eqs. (9) and (10), respectively.

\subsection{Load Capacity of Concentrically Loaded Column Specimens}

\subsubsection{Steel Reinforced Specimens (Group RS)}

272 When a column is subjected to a concentric load $(e=0)$, the column shortens uniformly with increasing load. The longitudinal strains in the steel reinforcement and concrete are equal at all stages of loading [27]. ACI 318-14 [27] uses the following equation to represent the axial load capacity of conventional steel reinforced concrete columns under concentric loading:

$$
P_{o}=0.85 f_{c}\left(A_{g}-A_{s t}\right)+f_{s y} A_{s t}
$$

276 where $f_{\mathrm{c}}$ is the concrete compressive strength; $A_{\mathrm{g}}$ is the gross sectional area of concrete; $A_{\mathrm{st}}$ is

277 the total area of longitudinal reinforcement; and $f_{\text {sy }}$ is the yield strength of the longitudinal 278 reinforcement.

279 For Specimen RS-0, the predicted axial load capacity using Eq. (11) and the concrete strength 280 at the first day of testing $\left(f_{\mathrm{c}}=31 \mathrm{MPa}\right)$ is $1394 \mathrm{kN}$. Therefore, the ratio of the experimental axial capacity to the predicted value is 0.968 . Some possible reasons for the theoretical capacity being slightly higher than the experimental value may be due to misalignment in the reinforcement or due to the variation in concrete strength.

\subsubsection{GFRP Reinforced Specimens (Group RF)}

285 The current American guide, ACI 440.1R-15 [1] states the contribution of FRP bars should 286 be neglected when used as reinforcement in columns. Similarly, the Canadian standard, CSA 287 S806-12 [28] allows the use of FRP bars as longitudinal reinforcement in axially loaded 
columns only, but ignores the compressive contribution of the FRP bars when calculating the ultimate axial capacity, as shown in Eq. (12).

$$
P_{o}=\alpha_{1} f_{c}\left(A_{g}-A_{f}\right)
$$

290 where $\alpha_{1}=0.85-0.0015 f_{c} \geq 0.67$; and $A_{\mathrm{f}}$ is the total cross-sectional area of the 291 longitudinal GFRP bars.

292 Based on the literature, other equations have been developed to predict the nominal axial 293 capacity of the GFRP reinforced concrete specimen. Tobbi et al. [29] showed that ignoring 294 the compressive contribution of the GFRP bars in Eq. (12) underestimates the maximum axial capacity. Therefore, the compressive contribution of the GFRP bars to the overall column capacity was taken into account. This was done by considering the GFRP bars compressive contribution to be $35 \%$ of the tensile strength as suggested by Kobayashi and Fujisaki [25], as 298 shown in Eq. (13).

$$
P_{o}=0.85 f_{c}\left(A_{g}-A_{f}\right)+0.35 f_{f t u} A_{f}
$$

where $f_{\mathrm{ftu}}$ is the tensile strength of the longitudinal GFRP bars

Tobbi et al. [30] proposed the most recent equation to calculate the nominal axial capacity, which also takes into account the compressive contribution of the GFRP longitudinal bars. In this equation, the compressive contribution of the GFRP longitudinal bars is calculated based on the elastic theory and from the material properties as shown in Eq. (14).

$$
P_{o}=0.85 f_{c}\left(A_{g}-A_{f}\right)+\varepsilon_{o} E_{f} A_{f}
$$

304 where $\varepsilon_{o}$ is the concrete strain at peak stress which is equal to 0.003 as defined by ACI 31814 [27]; and $E_{f}$ is the modulus of elasticity of the GFRP longitudinal reinforcement.

306 The ratios of the experimental axial capacity for the concentrically loaded column specimen

307 reinforced with GFRP bars (Specimen RF-0) as compared to the theoretical values obtained 
308 from Equations 12, 13 and 14 are shown in Table 3. It should be noted that the cross-

309 sectional area used in the calculations was determined on the GFRP bar's standard diameter

310 of $12.7 \mathrm{~mm}$ rather than by a value obtained from Immersion testing. Also the concrete

311 strength at the first day of testing was used in the formulas. Furthermore, it was assumed that

312 the compressive modulus was equal to the tension modulus as reported by Deitz et al. [26].

313 It can be seen that ignoring the contribution of the GFRP bars in Eq. (12) results in an

314 underestimation of the maximum capacity of $18.3 \%$. Furthermore, the ratio of the

315 experimental maximum load to the predicted value using Eq. (13) is below one with a value

316 of 0.892 . This value indicates that this equation over estimates the nominal axial capacity of

317 Specimen RF-0. On the other hand, Eq. (14) provides an under estimation of the maximum

318 capacity of $2.6 \%$. Therefore, Eq. (14) provided the most accurate estimate of the maximum

319 capacity and will be used in this study for the GFRP reinforced and GFRP encased

320 specimens.

321 4.2.3. GFRP Encased Specimens (Group I and C)

322 In this study, the same formula proposed by Tobbi et al. [30] is used to predict the axial

323 capacity of the GFRP encased specimens with the assumption that the strain in the GFRP

324 sections is approximately equal to the concrete ultimate strain, as shown in Eq. (14). The

325 compressive modulus of elasticity was used in the calculations with the total average values

326 from the web and flanges of the I-section adopted for those specimens (Global value in Table

327 1). For the C-sections, compression testing of only the webs was performed and hence the

328 compression modulus of elasticity of such was adopted in calculating the axial capacity for

329 Group C specimens. Furthermore, the actual measured dimensions of the cross-sections were

330 slightly smaller than the nominal dimensions provided by the manufacturer. Therefore, the

331 measured dimensions were used to determine the cross-sectional areas. 
332 The ratios of the experimental axial capacity for the concentrically loaded specimen

333 reinforced with GFRP sections (Specimens I-0 and C-0) as compared to the theoretical values

334 obtained from Eq. (14) are shown in Table 4. It can be seen that there is a reasonable and

335 accurate agreement between the experimental and calculated load capacity for these columns,

336 especially for Specimen C-0.

\subsection{Theoretical P-M Interaction Diagrams}

An analytical axial load-bending moment (P-M) interaction diagram was plotted to represent the axial load $(\mathrm{P})$ and corresponding bending moment $(\mathrm{M})$ of each of the specimens. A number of assumptions consistent with those applicable to steel reinforced cross sections were used in the analysis to develop the theoretical P-M interaction diagrams of GFRP reinforced and GFRP encased concrete cross-sections. These assumptions are as follows:

- The distribution of strain is assumed to be linear along the height of the section or in other words plane sections remain plane after deformation.

- Strain compatibility exists between the constituent materials, i.e. concrete, steel and GFRP reinforcement and sections, such that a perfect bond is assumed amongst these materials

- In tension, concrete is weak and therefore its tensile strength is ignored

- The steel reinforcing bars behave as an elastic-perfectly plastic material in both tension and compression as shown in Figure 4.

- The GFRP reinforcing bars and GFRP pultruded sections behave as a linear brittle material with orthotropic properties, as shown in Figure 5.

- For the GFRP pultruded sections, only the flanges in compression and flanges in tension is assumed to contribute to the compressive and tensile resistance, respectively. In other words, the compressive and tensile resistance of the web of both the I-sections and C-sections is neglected. Furthermore, only the longitudinal tensile 
and compressive properties were used in the analysis with the transverse properties ignored.

- The confinement effect of the lateral steel and GFRP stirrups is ignored.

- The stress-strain model of Yang et al. [19] for unconfined concrete in compression is adopted as defined in 'Material Properties and Theoretical Considerations' above.

- Considering the column specimens are considered as short specimens, the effects of slenderness was not taken into account when determining the theoretical P-M interaction relationships.

365 For calculation of the axial load capacities and moment capacities under eccentric loads and pure bending, two methods were analysed. The first method is the conventional rectangular stress block method to construct the interaction diagrams of steel RC columns following the Australian Standard AS3600 - 2009 [20]. The second method is the small strips concrete method as described by Yazici and Hadi [31]. What varies in the two methods is the approach to determining the concrete response in compression.

In the rectangular stress block method, the concrete compressive stresses are assumed to be uniform along the cross section along a depth of $\gamma \mathrm{d}_{n}$ as shown in Figure 6, with the compressive force in the concrete determined by Eq. (15) for specimens of Group RS and RF.

374 The rectangular stress block method was not implemented for specimens of Group I and C.

$$
C_{c 1}=\alpha_{2} f_{c} b \gamma d_{n}
$$

375 where, $f_{c}$ is the concrete compressive strength on the first day of testing ( $\left.31 \mathrm{MPa}\right) ; d_{\mathrm{n}}$ is the

376 neutral axis depth from the top of the section; $\alpha_{2}=1.0-0.003 f_{c}$ within the limits $0.67 \leq$ 377 $\alpha_{2} \leq 0.85$; and $\gamma=1.05-0.007 f_{c}$ within the limits $0.67 \leq \gamma \leq 0.85$. 
378 On the other hand, in the small strips method the concrete cross section is assumed to consist 379 of small finite parallel strips with a thickness $(t)$ of $1 \mathrm{~mm}$ and a width equal to the cross 380 section width $(b)$ of $210 \mathrm{~mm}$, as shown in Figure 7. The number of strips $(n)$ is equal to the 381 depth of the cross section of $210 \mathrm{~mm}$ divided by the thickness of each strip. Therefore, the 382 cross section was divided into 210 small strips. Based on the assumption that strain 383 distribution is linear along the height of the section after bending, the strain in the centre of 384 each strip $\left(\varepsilon_{c, n}\right)$ can be calculated, by assuming the extreme concrete compressive fiber has 385 reached the ultimate compressive strain of 0.003 as shown in Eq. (16). After calculating the 386 strain in each concrete strip, the corresponding stress value $\left(f_{c, n}\right)$ on the centre of each strip is 387 calculated according to the stress-strain model for unconfined concrete explained above. With 388 the basic assumption that the tensile strength of concrete is ignored in the calculations, the 389 stresses corresponding to tensile strains (i.e. $\varepsilon_{c, n}<0$ ) are assumed to be zero. After

390 determining the stresses, the force reaction in the centre of each concrete strip $\left(C_{c, n}\right)$ is 391 calculated from Eq. (17) for specimens of Group RS and RF and from Eq. (18) for specimens 392 of Group I and C. The difference in these two formulas will be explained below. The moment 393 created by the force on each strip is calculated as the force in each strip multiplied by the 394 distance to the centreline of the section as shown in Eq. (19). Therefore, the overall response 395 of the concrete section is calculated as the summation of the forces acting on the strips, as 396 shown in Eq. (20). In addition, the overall moment response of the concrete section is 397 calculated as the summation of the moments with respect to the centreline of the section.

$$
\begin{gathered}
\varepsilon_{c, n}=0.003 \times \frac{d_{n}-\left(n-\frac{1}{2}\right)}{d_{n}} \\
C_{c, n}(\text { Specimens } R S \& R F)=f_{c, n} \times A_{c, \text { strip }}
\end{gathered}
$$




$$
\begin{gathered}
C_{c, n}(\text { Specimens I \& } C)=f_{c, n} \times\left(A_{c, \text { strip }}-A_{G F R P, n}\right) \\
M_{c, n}=C_{c, n}\left[\frac{D}{2}-\left(n-\frac{1}{2}\right)\right] \\
C_{c, 2}=\sum_{n=1}^{210} C_{c, n}
\end{gathered}
$$

398 where, $\mathrm{n}=1,2,3, \ldots . .210^{\text {th }}$ strip starting from the top of the section; $A_{\text {c.strip }}$ is the gross 399 concrete cross sectional area for each strip $(b \times t)$; and $A_{\mathrm{GFRP}, \mathrm{n}}$ is the area of the GFRP $400 \quad$ sections in the $\mathrm{n}^{\text {th }}$ strip.

401 In both these methods the same approach is taken to find the stresses and forces in the tensile 402 and compressive reinforcement. First the strains in the tensile and compressive reinforcement 403 or flanges of the GFRP sections are calculated using similar triangles with the assumptions of 404 linear strain distribution and the strain in the extreme concrete compressive fibre has reached the ultimate compressive strain of 0.003 . The tensile strains are considered negative while the compressive strains are positive. The stress in each layer of reinforcement or flanges of the

407 sections is then calculated by applying the stress-strain relationships for the constitutive 408 materials (see Section 4.1). The forces in the reinforcement are calculated as the stresses multiplied by the area. However, it is important to note that the compressive response of the concrete using Eq. (15) and Eq. (17) for Specimens RS and RF does not take into account the

411 existence of the compression reinforcement (top layer of bars) occupied in the concrete 412 compression zone. Therefore, to take into account the compression reinforcement in the 413 calculations, the force in the compression reinforcement is calculated using Eq. (21) and (22) 414 such that if the top layer of bars is within the concrete compression zone, it is necessary to 415 subtract $0.85 f_{\mathrm{c}}$ multiplied by the cross-sectional area of the bars in the top layer from the total 416 force contribution of those bars. Both Eq. (21) and Eq. (22) are for the rectangular stress 
417 block method. The same equations exist for the small strips method but the concrete 418 compression zone occupies a height of $d_{\mathrm{n}}$ instead of $\gamma d_{\mathrm{n}}$. Furthermore, for the bottom layer of 419 reinforcement these equations were not applied and the force in that layer was simply 420 calculated as the stress in that layer multiplied by the area even if that layer of bars occupied 421 the concrete compression zone. On the other hand, a slightly different approach was taken for specimens of Group I and $\mathrm{C}$ to take into account the existence of the GFRP sections $\left(A_{\mathrm{GFRP}, \mathrm{c}}\right)$ occupied in the concrete compression zone for the small strips method. This was done by subtracting the area of the GFRP sections, including flanges and also the webs, located in each concrete strip in the compression zone as shown in Eq (18). The forces for either the top or bottom flanges for Group I and C specimens were simply calculated as the area of the flanges (shaded regions in Figure 8) multiplied by the stresses in the flanges with positive force denoting compression and negative force implying tension. As mentioned above, the force contribution of the webs were neglected. It is important to note that the rectangular 430 stress block was not used for specimens of Groups I and C as it was quite complex to take 431 into account the areas of the GFRP sections located in the concrete compression block and 432 the corresponding lever arms and hence only the small strips method was utilised for these 433 specimens considering each concrete layer is analysed separately instead of one whole block.

$$
\begin{array}{lc}
\text { If } \gamma d_{n}<d_{c o}: & C=f_{\text {comp }} A_{\text {comp }} \\
\text { If } \gamma d_{n}>d_{c o}: & C=f_{\text {comp }} A_{\text {comp }}-0.85 f_{c} A_{\text {comp }}
\end{array}
$$

434 where, $d_{\text {co }}$ is the distance from the top of the section to the centre of the top layer of 435 reinforcement; and $f_{\mathrm{c}}$ is the concrete compressive cylinder strength at the first day of testing.

436 Therefore, using the two methods the axial load carrying capacity is equal to the summation 437 of forces acting on the reinforcement, forces acting on the flanges of the GFRP encased 438 sections and the forces acting on the concrete compressive section. Similarly, the moment 
439 carrying capacity is equal to sum of the moments with respect to the centreline of the section

440 under a given eccentricity. The applied eccentricity is equal to the bending moment capacity

441 divided by the axial load capacity.

442 The theoretical load-moment interaction diagrams for each method were drawn based on 443 twelve data points. The first point represents the axial load capacity of the specimens under 444 concentric loading with no applied eccentricity. The axial capacity for all the groups of 445 specimens loaded concentrically were as explained in the above section of 'Load Capacity of 446 Concentrically Loaded Column Specimens'. The rest of the points represent the axial load and bending moment capacity specimens loaded with a combined axial load and bending moment with the second point expressing the data point of the $25 \mathrm{~mm}$ eccentric loaded specimen. The rest of the data points are obtained with gradually increasing the eccentricity up until the pure bending condition. The process is as follows.

451 Using the goal seek function in Excel, the applied eccentricity is set to the required value by 452 changing only the neutral axis depth value $\left(d_{\mathrm{n}}\right)$. The eccentricity is calculated as the moment 453 capacity divided by the load capacity. The goal seek function determines the corresponding 454 strains, stresses and force components acting in the reinforcement and concrete strips or 455 blocks and subsequently determines the respective axial and bending moment capacities to obtain the set chosen value of eccentricity, by only changing the neutral axis depth input.

457 This process is repeated by varying the eccentricity value to obtain the data points on the 458 load-moment interaction diagram up until the pure bending condition. As mentioned above, 459 the compressive strength at the first day of testing was used to develop the theoretical P-M 460 interaction diagrams. Simply using the 28 day cylinder compressive strength of concrete 461 would underestimate the theoretical P-M interaction diagrams. 


\subsection{Analytical versus Experimental Results}

463 Plotting an experimental P-M diagram based on four points of loading would not accurately

464 predict the load and bending moment capacities especially when all the loading points are not 465 identified, most notably the balanced points. Therefore, the first maximum load $\left(P_{\max }\right)$ and 466 corresponding bending moment capacities $\left(M_{\exp }\right)$ of the experimentally tested specimens, as 467 shown in Table 2, were plotted as points on the theoretical P-M interaction diagrams.

468 Although the eccentrically loaded GFRP reinforced and GFRP encased specimens were able 469 to sustain a slight increase in load after $P_{\max }$ [11], the eventual failure after this second peak 470 load $\left(P_{\text {peak }}\right)$ was brittle and explosive with no warning signs with failure occurring at or not 471 long after this load, as shown in Figure 3 [11]. As a result, the analytical axial load-bending 472 moment diagrams were drawn for the GFRP reinforced and encased specimens 473 corresponding to the first maximum load $\left(P_{\max }\right)$ before the activation of the confinement 474 effect of the stirrups and thus just before the onset of concrete spalling. Therefore, the confinement effect of the lateral steel and GFRP stirrups is ignored and an unconfined concrete model was adopted in the analysis.

The theoretical P-M interaction diagrams and the experimental results for all the groups of specimens are shown in Figures 9 - 12. For comparison purposes, the theoretical load and bending moment capacities for the $25 \mathrm{~mm}$ and $50 \mathrm{~mm}$ eccentrically loaded specimens were plotted as circular data points on the P-M diagram, in order to compare the same values obtained experimentally which were denoted by the square data points. It should be noted that the results of the GFRP reinforced and GFRP encased beam specimens were not presented and plotted against the theoretical P-M diagrams as the failure of these beam specimens prepared were in shear or bearing rather than in flexure and there were inconsistencies in the testing of these specimens as discussed in Hadi and Youssef [11]. In addition, the experimental results of the GFRP reinforced beam specimen could not be 
compared to the theoretical models. Further research elaboration is necessary to investigate the beams by taking into account ACI 440.1R - 15 [1] provides guidelines for the flexure design of FRP reinforced beams designed to be controlled by either concrete crushing or FRP rupture.

491 The experimental load and moment capacities of the steel reinforced specimens (Group RS)

492 for all loading types were close to the theoretical P-M diagrams for both methods, as shown

493 in Figure 9. All the experimental data points except for the pure compression point lied above 494 the P-M diagram using the small strips method. However, for the rectangular stress block P495 M diagram, the data point of the $25 \mathrm{~mm}$ eccentric loaded specimen was slightly under the P$496 \mathrm{M}$ interaction diagram, with the theoretical load capacity being $3.9 \%$ greater than the 497 experimental load capacity. Some possible reasons for the theoretical load capacity of this 498 data point being slightly higher than the experimental value may be due to either 499 misalignment in the reinforcement or variation in concrete strength or specimen alignment 500 errors. Therefore, the P-M diagram developed from the small strips method provided a more 501 conservative estimate of the load and bending moment capacities as compared to the 502 rectangular stress block. In general, both the developed theoretical models yielded results that 503 are comparable to the experimental results for Group RS specimens.

504 For the GFRP reinforced specimens (Group RF), the effect of the compressive contribution of 505 the GFRP bars when determining the P-M interaction diagram was investigated. A total of 506 two theoretical diagrams were drawn with the first including the compressive contribution of 507 the GFRP bars by assuming the modulus in compression is equal to the modulus in tension 508 (i.e. $E_{\mathrm{fc}}=E_{\mathrm{ft}}$ ), as shown in Figure $10 \mathrm{a}$, whereas the second ignored the compressive contribution of the bars (i.e. $E_{\mathrm{fc}}=0$ ), as shown in Figure $10 \mathrm{~b}$. 
510 When taking into account the compressive contribution of the GFRP bars the experimental

511 result of the concentrically loaded and $50 \mathrm{~mm}$ eccentrically loaded specimens (RF-0 and RF-

512 50) yielded values above the theoretical P-M diagram using the small strips method with

513 comparable results, as shown in Figure 10a. However, the data point of the $25 \mathrm{~mm}$

514 eccentrically loaded specimen fell below the theoretical P-M diagram developed by the small

515 strips method. Errors in testing may be the reason for the low experimental results. This can

516 be seen in the load versus axial deformation curves for the four groups of specimens loaded

517 in $25 \mathrm{~mm}$ eccentricity, as shown in Figure 13. The initial slope of the load-displacement

518 curve of Specimen RF-25 was lower than that of the other specimens. This could be due to

519 errors in aligning the specimen resulting in load not being applied exactly at $25 \mathrm{~mm}$

520 eccentricity [11]. Furthermore, the failure location of the internal reinforcement of this

521 specimen was located at the top of the specimen rather than at mid-height [11]. On the other hand, the experimental results of the eccentrically loaded specimens yielded values below the theoretical P-M diagram using the conventional rectangular stress block method. Therefore,

524 when taking into account the compressive contribution of the GFRP bars, the small strips

525 method provided a more accurate approximation of the experimental loads and bending moment capacities for Group RF specimens for the different types of loading as compared to

527 the conventional rectangular stress block method.

528 When ignoring the compressive contribution of the GFRP bars, the axial load capacity in pure compression is decreased as the second part Eq. (14) is reduced to $0\left(E_{\mathrm{fc}}=0\right)$ providing a conservative approach for the concentric loading condition. It should be noted that similar to Specimen RF-25, Specimen RF-50 also failed at the top of the specimen rather than in the

532 instrumented region as discussed in [11]. Having said this, the $50 \mathrm{~mm}$ eccentrically loaded 533 column shows good agreement with the interaction diagram for this case with the experimental data point above the theoretical diagram for the two methods. However, the 25 
$535 \mathrm{~mm}$ eccentrically loaded column falls below the rectangular stress block method diagram but 536 shows relatively good agreement with the small strips method, although the experimental 537 load capacity value is $3.4 \%$ lower than that obtained theoretically using the small strips 538 method. As mentioned above errors in testing of this column did occur. In general, 539 considering that the compressive properties of FRP bars has not been extensively understood, 540 especially when embedded in concrete, it is safer to say that ignoring the compressive contribution of the GFRP bars and drawing the theoretical P-M diagram based on the small strips method is the most accurate and safe alternative for the design of such columns at this

543 stage. Having said this, for the small strips method further consideration of the maximum 544 stress limited to the concretes stress-strain curve to allow for differences between the cylinder 545 strength and in-place column specimen strengths, which may vary between $0.85 f_{\mathrm{c}}$ to $0.9 f_{\mathrm{c}}$, as well as each specimen's strength at the respective day of testing should be taken into account when drawing the P-M diagrams as explained below with the conclusions slightly varying.

548 Considering that the theoretical P-M diagrams were drawn based on the concrete compressive strength at the first day of testing and knowing that the strength of concrete is ever increasing, a discussion of the effects of this is necessary. The concentric specimens were tested first, followed by the $25 \mathrm{~mm}$ eccentrically loaded specimens than the $50 \mathrm{~mm}$ loaded specimens and

552 lastly the beam specimens. The concrete strength of each specimen tested on each day could 553 be determined based on a linear trend of the known concrete compressive strength determined at each day tested. The increase in concrete strength for each specimen tested on a different day will shift the theoretical P-M diagrams upwards, since the load and bending moment capacity will increase. Therefore, the relationship between the experimental data

557 points as a comparison to these revised theoretical P-M diagrams should be taken into 558 account. In summary with the slight increase in concrete strength for each specimen, it was 559 realised that although the revised P-M diagrams would be shifted slightly upwards for both 
560 methods, with the experimental data point of RF-50 now slightly below the P-M diagram for

561 the small strips method (when $E_{\mathrm{fc}}=E_{\mathrm{ft}}$ ) and rectangular stress block method (when $E_{\mathrm{fc}}=0$ ), the

562 same outcomes and conclusions stated above for Group RS and RF specimens were

563 acceptable. Therefore, the small strips method for predicting the P-M interaction relationship

564 was a more safe and accurate approach as compared to the rectangular stress block method.

565 Furthermore, ignoring the compressive contribution of the GFRP bars is also the best method

566 for those specimens.

567 Furthermore, it should be noted that the Australian standard AS3600 - 2009 [20] mentions

568 that if a stress-strain relationship is used for concrete, the maximum stress of the concrete

569 shall be modified to $0.9 f_{\mathrm{c}}$. In the standard the parameter $f_{\mathrm{c}}$ denotes the characteristic

570 compressive cylinder strength of concrete at 28 days $\left(f_{\mathrm{c}}\right.$ ' $)$, but in this study $f_{\mathrm{c}}$ will be

571 represented as the concrete strength at the first day of testing, as mentioned above. In this

572 study the maximum stress was limited to $0.85 f_{\mathrm{c}}$ as explained in Section 4.1 to take into

573 account size and shape effects between the cylinders and column specimens. If the maximum

574 stress is modified to $0.9 f_{\mathrm{c}}$ the P-M diagram for the specimens of Group RS and RF developed

575 using the small strips method will shift upwards to just slightly under the diagram developed

576 using the rectangular stress block method, as shown in Figure 14. However, in terms of the

577 Group RF specimens, the experimental data points are more matched or appropriate at this

578 stage with the level of knowledge on GFRP reinforced columns to the values obtained by the

579 small strips method using a maximum stress of $0.85 f_{c}$ rather than those obtained by the

580 rectangular stress block method, as explained above and shown in Figure 10 and Figure 14.

581 Most notably, when utilising the small strips method with a maximum stress of $0.9 f_{\mathrm{c}}$ and

582 assuming $E_{\mathrm{c}}=0$ (Figure 14), the data point of Specimen RF-50 is above the P-M diagram

583 when using the concrete strength at the first day of testing but when using the concrete

584 strength at the day of testing the specimen (as explained above), the experimental load 
capacity is just slightly lower than that of the theoretical value whereas the theoretical moment capacity is similar to the experimental value. Therefore, for the GFRP reinforced specimens it is recommended to limit the maximum concrete stress to $0.85 f_{\mathrm{c}}$ and neglect the compressive contribution of the bars as a conservative approach for design. Having said this, further experimental verification of the theoretical P-M diagrams is required for the GFRP 590 reinforced specimens.

591 On the other hand, for both the GFRP I-section and C-section encased specimens, the 592 developed theoretical models using the small strips method utilising a maximum stress of $593 \quad 0.85 f_{\mathrm{c}}$ yielded results that were conservative as compared to the experimental results, as shown in Figures 11 and 12. This may be due to the assumption of using only the flanges of the sections for the determination of the forces. If the contributions of the webs of these sections are taken into account, the theoretical load and moment interaction diagram will shift upwards. Having said this, considering the limited studies and the orthotropic nature of the

598 GFRP pultruded material as well as the high dispersion in compressive properties it is safer to have a higher factor of safety for the members encased with such materials. Further research is required to fully develop and understand the P-M interaction diagrams of these specimens. It is interesting to note that although Specimen C-B showed signs of a typical shear failure and was not plotted in Figure 12, the experimental bending moment capacity of this specimen was well above the theoretical prediction. In fact, the experimental bending moment of 43.4 kN.m was approximately $46 \%$ higher than that obtained by the theoretical approach.

605 It should be noted that the strains in tension and compression in the GFRP bars and GFRP sections for all the points along the interaction diagram were checked in terms of the ultimate strains even when the compressive contribution of the GFRP bars were neglected. No failure in these bars or flanges of the sections occurred when the strain in concrete reached its ultimate value of 0.003 . The compressive ultimate strain of the GFRP bars was calculated by 
610 assuming the compressive modulus was equal to the tension modulus and the compressive

611 strength was equal to $50 \%$ of the tensile strength as reported by Deitz et al. [26]. It should be

612 noted that as mentioned above in the preliminary testing of the GFRP sections, potential

613 premature failure may have occurred for these sections when tested in compression due to

614 local end crushing, local end brooming, or geometric instabilities. This premature failure will

615 result in a lower rupture strain and compressive strength obtained but will not affect the

616 compressive modulus, which is determined as the initial slope of the stress and strain curves.

617 In drawing the P-M interaction diagram, the theoretical strain in compression was checked

618 against the rupture strain obtained from the compression testing and it was found that at the

619 first peak load no failure of the flanges of the sections occurred. Further investigation into the

620 compressive properties of these materials is required before they can be properly used in 621 design and construction.

622 As an extension, the strain data obtained from the steel and GFRP reinforcement in 623 compression and tensile were used to determine the experimental neutral axis for the 624 specimens loaded in 25 and $50 \mathrm{~mm}$ eccentricity, which led to calculating the load and 625 bending moment capacities. This was done by assuming linear strain distribution and by 626 calculating the concrete response using the small strips method. Furthermore, only Specimens 627 RS and RF were investigated since the assumption of neglecting the contribution of the webs 628 of the GFRP encased specimens would not provide a good comparison with the experimental 629 values. Table 5 shows the comparison of the capacities by three methods; obtained 630 experimentally, by the small strips method utilising a maximum concrete stress of $0.85 f_{\mathrm{c}}$ and 631 assuming concrete has reached ultimate strain of 0.003 as explained above and by using the 632 strain gauge data. Unfortunately, the strain reading of the GFRP bar in compression for 633 Specimen RF-25 was lost and therefore it was assumed to be equal to the value obtained for 634 Specimen RS-25 of $0.374 \%$. It can be seen that good correlation in the capacities obtained by 
635 the three methods was obtained for Specimens RS-50 and RF-50 when assuming the 636 compressive modulus is equal to zero. However, when assuming the compressive and tensile

637 moduli are equal for Specimen RF-50, the moment capacity obtained by the strain gauge data 638 is $4 \%$ higher than that obtained experimentally. On the other hand, there was not a good 639 correlation in the capacities for Specimens RS-25 and RF-25, with the moment capacities 640 calculated using the strain gauge data much higher than those obtained experimentally, while 641 the load capacities also varied considerably, as shown in Table 5. This was also the case for

642 Specimens I-25 and C-25. This would question the accuracy of the strain gauge data for the 643 tensile reinforcement in the $25 \mathrm{~mm}$ eccentrically loaded specimens which may be prone to 644 sensitivity issues with the bars subjected to small values of compressive and tensile strains 645 close to the maximum load. Furthermore, as mentioned above only one strain gauge was 646 placed on the tension and compression longitudinal bars and sections and no average could be

647 obtained for each value. Also un-warranted premature stressing of the bars from the pouring 648 of concrete and curing could cause some issues. It should be noted similar conclusions were 649 drawn when the rectangular stress block method was utilized in conjunction with the strain 650 gauge data to obtain the capacities when compared with the theoretical values obtained by the 651 same method along with the experimental values.

\section{$652 \quad 6.0$ Parametric Study}

653 The analytical model was used to study the effects of two main parameters on the structural 654 performance of GFRP reinforced square concrete columns in terms of the interaction 655 diagrams. The parameters studied are: (a) concrete compressive strength $\left(f_{\text {co }}\right)$, and (b) 656 longitudinal GFRP reinforcement ratio. Only the small strips method utilising a maximum 657 stress of $0.85 f_{\mathrm{c}}$ was implemented to draw the $\mathrm{P}-\mathrm{M}$ interaction diagrams in this parametric 658 study and the compressive contribution of the GFRP bars was neglected. 
659 The cross-section dimensions and the material properties of the columns studied were the

660 same as that used in the experimental testing. The columns were square in cross-section with

661 a side width of $210 \mathrm{~mm}$. In addition, while the effect of each parameter was investigated, all

662 other parameters were kept constant. Therefore, default values of each parameter were set

663 when that parameter was not being used in the study. The following default values were set

664 for each parameter: the compressive strength of concrete at the first day of testing $\left(f_{\text {co }}\right)$ was 31

$665 \mathrm{MPa}$; the longitudinal GFRP reinforcement ratio was $1.15 \%$; and the ratio of the compressive

666 modulus to the tensile modulus was $0\left(E_{\mathrm{fc}}=0\right)$. Essentially these values were the same as

667 those of the experimentally tested specimens.

\subsection{Influence of Concrete Strength, $f_{c o}$}

669 Depending on the quality control that is implemented, variations in concrete strengths most

670 likely occur. Therefore, it is important to study the effects of varying the concrete 671 compressive strength on the structural behaviour of GFRP reinforced concrete columns. A

672 total of four concrete strengths were studied as follows: 31, 40, 50 and $60 \mathrm{MPa}$. The P-M strength interaction diagram for all the different cases is shown in Figure 15. It should be noted that the formula for the Young's modulus of concrete also varies for strengths over 40 MPa. As expected, as the concrete strength increases, so does the load and bending moment capacities. The strains in the tension and compression bars for all the points along the interaction diagram were checked in terms of the ultimate strains for each case and no failure in these bars occurred for all concrete strengths when the strain in concrete reached its ultimate value. In fact, as the concrete strength increased, the strains in the tensile bars at the ultimate bending condition $(P=0 \mathrm{kN})$ increased, but remained below the ultimate value. It was seen that a tensile strain of $1.4 \%$ was obtained at the ultimate bending condition when

682 the concrete strength at the first day of testing was $60 \mathrm{MPa}$ which is lower than the ultimate 683 value of $2.41 \%$. 
685 A total of four longitudinal GFRP reinforcement ratios were studied as follows: 1.15, 3, 5 and 7\%. The P-M strength interaction diagram for the different reinforcement ratios when neglecting the compressive contribution of the GFRP bars $\left(E_{\mathrm{fc}}=0\right)$ is shown in Figure 16a. It can be seen that as the reinforcement ratio increases, the axial load capacities for pure compression decreases slightly because the modulus in compression is reduced to zero and the second part of Eq. (14) becomes also zero. Furthermore, as the reinforcement ratios increases, the bending moment capacity at lower levels of load capacity increases.

692 It is interesting to see the behaviour of the P-M interaction diagram when taking into account the compressive contribution of the GFRP bars $\left(E_{\mathrm{fc}}=E_{\mathrm{ft}}\right)$ as shown in Figure 16b. Most notably, to calculate the axial capacity for pure compression the second part of Eq. (14) is taken into account unlike that when $E_{\mathrm{fc}}=0$. As a result, for this case as the reinforcement ratio increases so does the axial capacity for pure compression. On the other hand similar to

697 Figure 16a, as the reinforcement ratio increases the bending moment capacity at lower levels of load capacity increases. Therefore, as reported by Choo et al. [3] the P-M interaction diagrams of GFRP reinforced columns do not experience any balanced points, unlike that of steel reinforced columns.

701 Furthermore, for all the cases no failure occurred for the GFRP bars in tension or compression when the concrete reached the ultimate strain. In fact, as the reinforcement ratio increased, the strains in the tensile bars at the ultimate bending condition $(P=0 \mathrm{kN})$

704 decreased.

\subsection{Conclusions}

706 Based on the experimental results and the analytical analysis of this study it can be concluded that concrete columns reinforced with GFRP bars and encased with pultruded GFRP sections 
can be potentially analysed using the same procedure used for conventional steel reinforced concrete columns. The small strips method adopted in this study for predicting the P-M

710 interaction relationship provided more accurate results as compared to the rectangular stress

711 block method for the GFRP reinforced specimens. Furthermore, considering that the 712 compressive properties of FRP bars has not been extensively understood, especially when 713 embedded in concrete, it is safer to say that ignoring the compressive contribution of the 714 GFRP bars and drawing the theoretical P-M diagram based on the small strips method is the 715 most accurate and safe alternative for the design of such columns at this stage. Further 716 experimental verification of the theoretical P-M diagrams is required for the GFRP reinforced 717 specimens considering the limited number of specimens in this study, the value of the 718 maximum stress on the stress-strain diagram for concrete (varies between $0.85 f_{\mathrm{c}}$ to $0.90 f_{\mathrm{c}}$ ) and the strength of each specimen on the respective day of testing.

720 In terms of the GFRP encased specimens, the small strips method provided satisfactory and 721 conservative estimates of the maximum load and bending moment capacities. It was found that the most accurate estimate of the maximum axial capacity for the GFRP reinforced specimen under concentric loading was achieved when taking into account the compressive contribution of the GFRP bars based on the elastic theory and assuming the strain in the bars is equal to the concretes ultimate compressive strain. Furthermore, in terms of the GFRP pultruded sections, a high dispersion in the compressive properties of these types of materials will require better testing procedures to prevent premature failures, better quality control at the manufacturing level, and further investigation into the compressive properties of these materials before they can be properly used in design and construction. In addition, the

730 experimental results of the GFRP reinforced and GFRP encased beam specimens could not

731 be compared to the theoretical models and further research elaboration is necessary to investigate this along with the P-M diagrams of GFRP encased specimens. 
733 Based on the parametric study, the load and bending moment capacities increase with the

734 increase in concrete strength. Furthermore, the interaction diagrams of GFRP reinforced

735 columns do not experience balanced points unlike that of steel reinforced columns. This study

736 is believed to give an understanding on the behaviour of GFRP reinforced and GFRP encased

737 concrete columns subjected to various loading conditions.

738 Acknowledgments

739 The authors would like to acknowledge the technical assistance of Messrs Alan Grant,

740 Fernando Escribano, Richard Gasser, Cameron Neilson, Duncan Best and Ritchie McLean.

741 The contribution of Ms. Philippa Langford is greatly appreciated. The first author would like

742 to thank the University of Wollongong, Australia for the support of his Ph.D. scholarship. 


\section{References}

744 [1] ACI 440.1R - 15, Guide for the Design and Construction of Structural Concrete 745 Reinforced with Fiber-Reinforced Polymer (FRP) Bars, American Concrete Institure, 746 Farmington Hills, MI, 2015

747 [2] N. Kawaguchi, Ultimate Strength and Deformation Characteristics of Concrete Members 748 Reinforced with AFRP Rods under Combined Axial Tension or Compression and Bending, 749 Fiber-Reinforced-Plastic Reinforcement for Concrete Structures, SP-138, A, (1993).

750 [3] C.C. Choo, I.E. Harik, H. Gesund, Strength of Rectangular Concrete Columns Reinforced 751 with Fiber-Reinforced Polymer Bars, ACI Structural Journal, 103 (3) (2006a) 452 - 459.

752 [4] C.C. Choo, I.E. Harik, H. Gesund, Minimum reinforcement ratio for fiber-reinforced 753 polymer reinforced concrete rectangular columns, ACI Structural Journal, 103 (3) (2006b) $754460-466$.

755 [5] H.J. Zadeh, A. Nanni, Design of RC columns using glass FRP reinforcement, Journal of 756 Composites for Constructions, 17(3) (2013) $294-304$.

757 [6] M.N.S. Hadi, H. Karim, M.N. Sheikh, Experimental Investigations on Circular Concrete 758 Columns Reinforced with GFRP Bars and Helices under Different Loading Conditions, 759 Journal of Composites for Construction, 10.1061/(ASCE)CC.1943-5614.0000670 (2015)

760 [7] J. Tomblin, E. Barbero, Local buckling experiments on FRP columns, Thin-Walled 761 Structures, 18(2) (1994) 97-116.

762 [8] A. Zureick, D. Scott, Short-term behaviour and design of fiber-reinforced polymeric 763 slender members under axial compression, 1(4) (1997) 140 - 149. 
764 [9] J.R. Correia, F.A. Branco, J. Ferreira, GFRP-concrete hybrid cross-sections for floors of 765 buildings, Engineering Structures, 31(6) (2009) 1331-1343.

766 [10] W.H. Kwan, M. Ramli, Indicative performance of fiber reinforced polymer (FRP)

767 encased beam in flexure, Construction and Building Materials, 48(0) (2013) 780-788.

768 [11] M.N.S Hadi, J. Youssef, Experimental Investigation of GFRP Reinforced and GFRP 769 Encased Square Concrete Specimens under Axial and Eccentric Load, and Four-Point 770 Bending Test, Journal of Composites for Construction, 10.1061/(ASCE)CC.19435614.0000675, (2016).

772

[12] AS1391-2007, Metallic materials - Tensile testing at ambient temperatures, Standards Australia, Sydney, Australia, 2007

774 [13] Pultrall, Inc. (2012). V-ROD - Specification HM, Thetford Mines, Canada, 775 www.pultrall.com

[14] ASTM D7205-11, Standard test method for tensile properties of fiber reinforced 777 polymer matrix composite bars, American Society for Testing and Materials, West Conshocken, PA, USA, 2011

[15] GRP (Glass Reinforced Products) (2008), Load Test of Pultruded Sections - Report Data, Lytton, Queensland, Australia (www.grpaustralia.com.au), accessed Aug. 08, 2014.

781 [16] ISO. 527-4, Determination of tensile properties of plastics. Part 4: Test conditions for 782 isotropic and orthotropic fiber-reinforced plastic composites, ISO, European Committee for 783 Standardisation, Brussels, Belgium, 1997

784 [17] ASTM D695-15, Standard test method for compressive properties of rigid plastics, 785 American Society for Testing and Materials, West Conshohocken, PA, 2015. 
[18] E.J. Barbero, S. Makkapati, J.S. Tomblin, Experimental determination of the compressive strength of pultruded structural shapes, Composites Science and Technology, 59(13) (1999) $2047-2054$.

[19] K.H. Yang, J.H. Mun, M.S. Cho, T.H.K. Kang, (2014), Stress-Strain Model for Various

[20] AS3600-2009, Concrete Structures, AS3600-2009, Standards Australia, Sydney, 792 Australia, 2009

[21] P.K. Mallick, Fiber Reinforced Composites, Material, Manufacturing, and Design, Marcell Dekker, Inc., New York, 1998, 469pp.

[22] W.P. Wu, Thermomechanical Properties of Fiber Reinforced Plastic (FRP) Bars, PhD dissertation, West Virginia University, Morgantown, WV,1990. 292 pp.

[23] M.R. Ehsani, Glass-Fiber Reinforcing Bars, Alternative Materials for the Reinforcement and Prestressing of Concrete, J.L. Clarke, Blackie Academic \& Professional, London, UK, 799 1993, pp. $35-54$.

800 [24] O. Chaallal, B. Benmokrane, Physical and Mechanical Performance of an Innovative 801 Glass-fiber-reinforced Plastic Rod for Concrete and Grouted Anchorage, Canadian Journal of 802 Civil Engineering, 20 (2) (1993) 254-268.

803 [25] K. Kobayashi, T. Fujisaki, Compressive behaviour of FRP reinforcement in non804 prestressed concrete members, 2nd International RILEM Symposium on Non-Metallic (FRP) 805 Reinforcement for Concrete Structures, E \& FN Spon, London, 267-274, 1995

806 [26] D.H. Deitz, I. E. Harik, H. Gesund, Physical properties of glass fiber reinforced polymer 807 rebars in compression, Journal of Composites for Construction, 7(4) (2003) $363-366$. 
808 [27] ACI 318-14, Building code requirements for structural concrete, American Concrete

809 Institute, Farmington Hills, MI, 2014.

810 [28] CSA S806-12, Design and Construction of Building Structures with Fiber-Reinforced

811 Polymers, Canadian Standards Association, Toronto, Canada, 2012

812 [29] H. Tobbi, A.S. Farghaly, B. Benmokrane, Concrete Columns Reinforced Longitudinally

813 and Transversally with Glass Fiber-Reinforced Polymer Bars, ACI Structural Journal, 109(4)

814 (2012) 551-558.

815 [30] H. Tobbi, A.S. Farghaly, B. Benmokrane, Behaviour of Concentrically Loaded Fiber-

816 Reinforced Polymer Reinforced Concrete Columns with Varying Reinforcement Types and

817 Ratios, ACI Structural Journal, 111(2) (2014) 375-386.

818 [31] V. Yazici, M.N.S Hadi, Axial Load-Bending Moment Diagrams of Carbon FRP

819 Wrapped Hollow Core Reinforced Concrete Columns, Journal of Composites for

820 Constructions, 13(4) (2009) $262-268$. 


\section{List of Figures}

824 Fig. 1. Plan view of reinforcement details for all groups of specimens

825 Fig. 2. Compression testing of pultruded GFRP sections

826 Fig. 3. Axial load-displacement relationships of column specimens with varying load

827 eccentricities: (a) Group RS; (b) Group I; (c) Group RF; and (d) Group C

828 Fig. 4. Stress-Strain Relationships of N12 longitudinal steel bar (a) Experimental; and (b)

829 Idealised

830 Fig. 5. Experimental and Idealised Stress-Strain Relationship of longitudinal GFRP bar

831 Fig. 6. Rectangular stress block method and force distribution of reinforcement for Group RS

832 and RF specimens

833 Fig. 7. Small strips method to determine the concrete compressive response

834 Fig. 8. Force distribution of specimens of Group I and C

835 Fig. 9. Comparison of theoretical P-M diagrams and experimental results for Group RS

836 specimens

837 Fig. 10. Comparison of theoretical P-M diagrams and experimental results for Group RF

838 specimens: (a) Compressive contribution of GFRP bars included $\left(\mathrm{E}_{\mathrm{fc}}=\mathrm{E}_{\mathrm{ft}}\right)$; and (b)

839 Compressive contribution of GFRP bars ignored $\left(\mathrm{E}_{\mathrm{fc}}=0\right)$

840 Fig. 11. Comparison of theoretical P-M diagrams and experimental results for Group I

841 specimens

842 Fig. 12. Comparison of theoretical P-M diagrams and experimental results for Group C 843 specimens

844 Fig. 13. Axial and lateral load-deflection curves of the $25 \mathrm{~mm}$ eccentrically loaded column 845 specimens, $\mathrm{e}=25 \mathrm{~mm}$

846 Fig. 14. Theoretical P-M diagrams of Group RF specimens when varying the maximum 847 stress of concrete from $0.85 f_{\mathrm{c}}$ to $0.9 f_{\mathrm{c}}$ and assuming $E_{\mathrm{fc}}=0$

848 Fig. 15. Influence of concrete strength on P-M interaction diagrams for Specimens RF 
849 Fig. 16. Influence of longitudinal GFRP reinforcement ratio on P-M interaction diagrams: (a) 850 Compressive contribution of GFRP bars ignored $\left(\mathrm{E}_{\mathrm{fc}}=0\right)$; and $(\mathrm{b})$ Compressive contribution 851 of GFRP bars included $\left(\mathrm{E}_{\mathrm{fc}}=\mathrm{E}_{\mathrm{ft}}\right)$ 
$852 \quad$ List of Tables

853

854 Table 1. Tensile and compressive properties of the GFRP pultruded sections (averages and 855 sample standard deviations)

856 Table 2. Experimental maximum load and bending moment capacities of specimens

857 Table 3. Experimental and theoretical axial capacity of Specimen RF-0

858 Table 4. Experimental and theoretical axial capacity of Specimen I-0 and C-0

859 Table 5. Comparison of load and bending moment capacities for eccentrically loaded 860 specimens reinforced with bars

861 
862 Table 1. Tensile and compressive properties of the GFRP pultruded structural sections

863 (averages and sample standard deviations)

\begin{tabular}{ccccc}
\hline & \multicolumn{3}{c}{ I-section Longitudinal } & C-section \\
\cline { 2 - 4 } Property & WEB & FLANGE & GLOBAL ${ }^{\mathrm{a}}$ & Longitudinal \\
\cline { 2 - 4 } & & & & WEB \\
\hline Tensile Strength (MPa) & $386.5 \pm 17.4$ & $430.2 \pm 32.7$ & $405.9 \pm 32.91$ & $318.1 \pm 31.8$ \\
Tensile Modulus (GPa) & $20.7 \pm 0.7$ & $26.0 \pm 2.2$ & $23.4 \pm 3.2$ & $27.1 \pm 2.1$ \\
Tensile Rupture Strain (\%) & $1.89 \pm 0.12$ & $1.70 \pm 0.23$ & $1.80 \pm 0.19$ & $1.22 \pm 0.10$ \\
& & & & \\
Compressive Strength (MPa) & $201.3 \pm 28.9$ & $221.4 \pm 34.3$ & $211.6 \pm 32.9$ & $275.4 \pm 74.1$ \\
Compressive Modulus (GPa) & $21.6 \pm 2.3$ & $22.4 \pm 2.3$ & $22.0 \pm 2.3$ & $25.6 \pm 2.7$ \\
Compressive Rupture Strain (\%) & $0.88 \pm 0.11$ & $0.91 \pm 0.14$ & $0.90 \pm 0.12$ & $0.96 \pm 0.14$ \\
\hline${ }^{\mathrm{a}}$ The average results of all the coupons extracted from the flange and web of the I-section
\end{tabular}


866 Table 2. Experimental maximum load and bending moment capacity of specimens

\begin{tabular}{|c|c|c|c|c|}
\hline Test & $1^{\text {st }}$ Maximum & Axial displacement & Lateral deflection & Bending Moment, \\
\hline \multirow[t]{2}{*}{ Specimen } & Load, & at $\mathrm{P}_{\max }$, & at $\mathrm{P}_{\max }$, & $\mathrm{M}_{\mathrm{exp}}=\mathrm{P}_{\max }(\mathrm{e}+\delta)$ \\
\hline & $\mathrm{P}_{\max }(\mathrm{kN})$ & $\Delta(\mathrm{mm})$ & $\delta(\mathrm{mm})$ & (kN.m) \\
\hline RS-0 & 1350 & 2.87 & 0 & 0 \\
\hline RS-25 & 995 & 2.72 & 2.11 & 27.0 \\
\hline RS-50 & 747 & 2.65 & 2.66 & 39.3 \\
\hline RS-B & 232 & - & $8.08^{\mathrm{c}}$ & $27.3^{\mathrm{d}}$ \\
\hline RF-0 & 1285 & 2.59 & 0 & 0 \\
\hline RF-25 & 803 & 3.00 & 2.21 & 21.9 \\
\hline RF-50 & 615 & 2.33 & 2.46 & 32.3 \\
\hline RF-B & $340^{\mathrm{a}}$ & - & $12.13^{\mathrm{c}}$ & $40.0^{\mathrm{d}}$ \\
\hline $\mathrm{I}-0$ & 1425 & 3.13 & 0 & 0 \\
\hline $\mathrm{I}-25$ & 1008 & 2.51 & 2.05 & 27.3 \\
\hline I-50 & 765 & 2.88 & 3.18 & 40.7 \\
\hline I-B & $216^{\mathrm{b}}$ & - & $13.47^{\mathrm{c}}$ & $25.3^{\mathrm{d}}$ \\
\hline $\mathrm{C}-0$ & 1385 & 3.24 & 0 & 0 \\
\hline $\mathrm{C}-25$ & 985 & 2.86 & 2.96 & 27.5 \\
\hline$C-50$ & 679 & 3.04 & 3.69 & 36.4 \\
\hline C-B & 370 & - & $12.78^{\mathrm{c}}$ & $43.4^{\mathrm{d}}$ \\
\hline
\end{tabular}

$867{ }^{\mathrm{a}}$ The shear zones of only this specimen were wrapped with two layers of CFRP sheets.

$868{ }^{\mathrm{b}}$ Failed prematurely by bearing. Data point could not be used on the P-M interaction diagram

$869{ }^{\mathrm{c}}$ Midspan deflection of the beam specimens

$870{ }^{\mathrm{d}}$ Calculated using Eq. (2). 
872 Table 3. Experimental and theoretical axial capacity of Specimen RF-0

\begin{tabular}{|c|ccc|ccc|}
\hline $\begin{array}{c}\text { Experimental maximum } \\
\text { axial load }\end{array}$ & \multicolumn{3}{|c|}{ Theoretical, $\mathrm{P}_{\mathrm{o}}(\mathrm{kN})$} & \multicolumn{3}{|c|}{$\frac{P_{\max }}{P_{o}}$} \\
\cline { 2 - 7 } \\
\cline { 2 - 6 }
\end{tabular}

873 
874 Table 4. Experimental and theoretical axial capacity of Specimen I-0 and C-0

\begin{tabular}{cccc}
\hline & Experimental & Theoretical & \\
Specimen & maximum axial load & $P_{\mathrm{o}}(\mathrm{kN})$ & $\frac{P_{\text {max }}}{P_{o}}$ \\
& $P_{\max }(\mathrm{kN})$ & Eq. (14) & 1.076 \\
\hline $\mathrm{I}-0$ & 1425 & 1324 & 1.015 \\
\hline
\end{tabular}

875

876 
877 Table 5. Comparison of load and bending moment capacities for eccentrically loaded

878 specimens reinforced with bars

\begin{tabular}{|c|c|c|c|c|c|c|c|}
\hline \multirow[t]{2}{*}{ Specimen } & \multicolumn{2}{|c|}{ Experimental } & \multicolumn{2}{|c|}{ Theory - Small } & \multicolumn{3}{|c|}{ Theory - } \\
\hline & $\mathrm{P}(\mathrm{kN})$ & $\mathrm{M}(\mathrm{kN} . \mathrm{m})$ & $\mathrm{P}(\mathrm{kN})$ & M (kN.m) & $\mathrm{P}(\mathrm{kN})$ & $\mathrm{M}(\mathrm{kN} . \mathrm{m})$ & $\mathrm{e}(\mathrm{mm})$ \\
\hline RS-25 & 995 & 27.0 & 980 & 24.5 & 887 & 31.1 & 35.1 \\
\hline RS-50 & 747 & 39.3 & 705 & 35.3 & 717 & 37.8 & 52.7 \\
\hline $\operatorname{RF}-25\left(E_{\mathrm{c}}=E_{\mathrm{t}}\right)$ & 803 & 21.9 & 884 & 22.1 & 713 & 31.9 & 44.7 \\
\hline $\operatorname{RF}-50\left(E_{\mathrm{c}}=E_{\mathrm{t}}\right)$ & 615 & 32.3 & 625 & 31.3 & 624 & 33.6 & 53.9 \\
\hline $\mathrm{RF}-25\left(E_{\mathrm{c}}=0\right)$ & 803 & 21.9 & 831 & 20.8 & 656 & 27.9 & 42.6 \\
\hline $\mathrm{RF}-50\left(E_{\mathrm{c}}=0\right)$ & 615 & 32.3 & 586 & 29.3 & 570 & 30.0 & 52.6 \\
\hline
\end{tabular}

$879{ }^{\mathrm{a}}$ Calculated by assuming concrete has reached ultimate compressive strain of 0.003 (refer to 880 Section 4.3)

$881{ }^{\mathrm{b}}$ Calculated from the experimental strain gauge data and calculating the concrete response 882 using the small strips method 


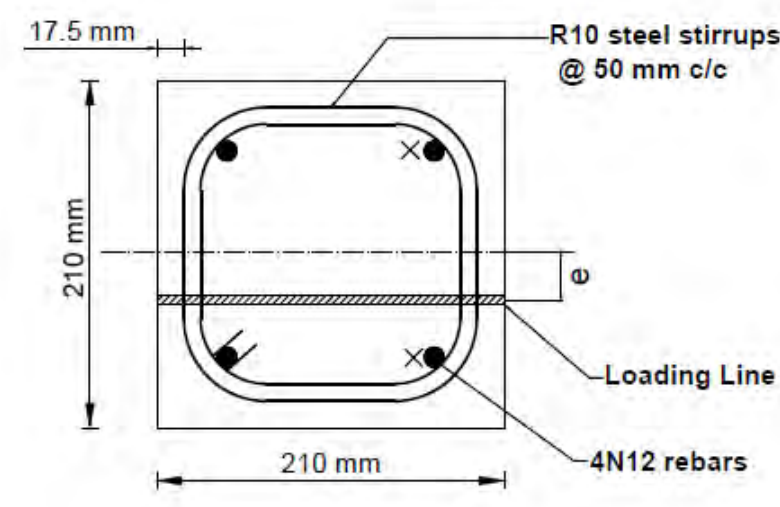

Group RS

(Reference Steel)

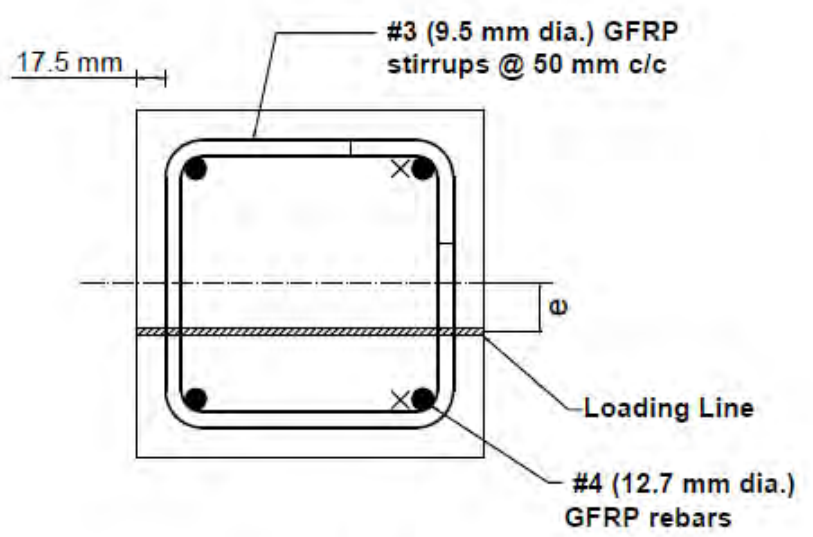

Group RF

(Reference GFRP)

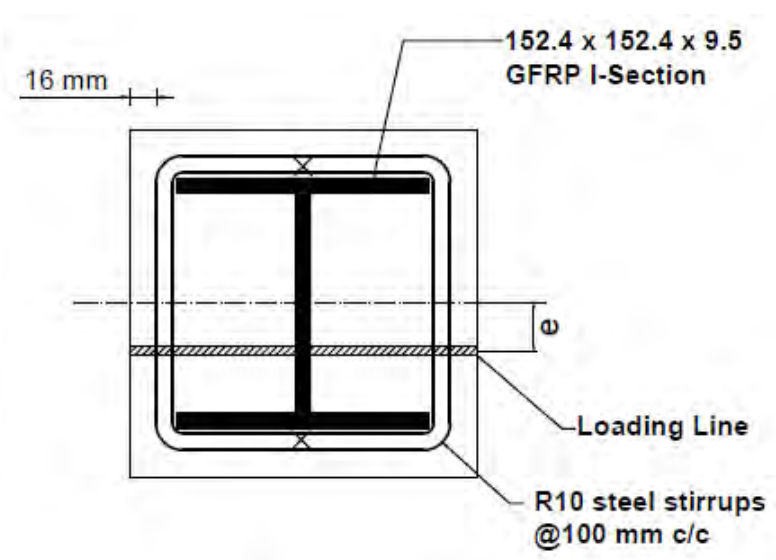

Group I

(I-section encased)

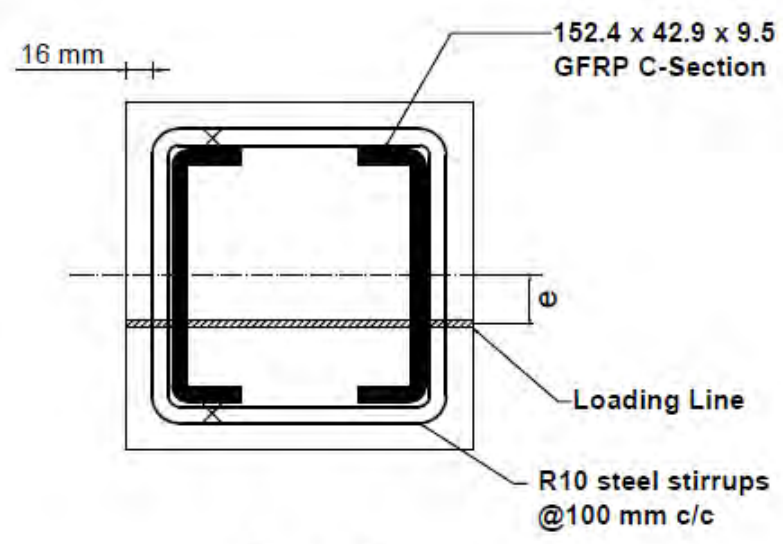

Group C

(C-section encased) $\times$ Strain gauge location on longitudinal bars and GFRP sections at the
mid-height of the specimens

Fig. 1. Plan view of reinforcement details for all groups of specimens 


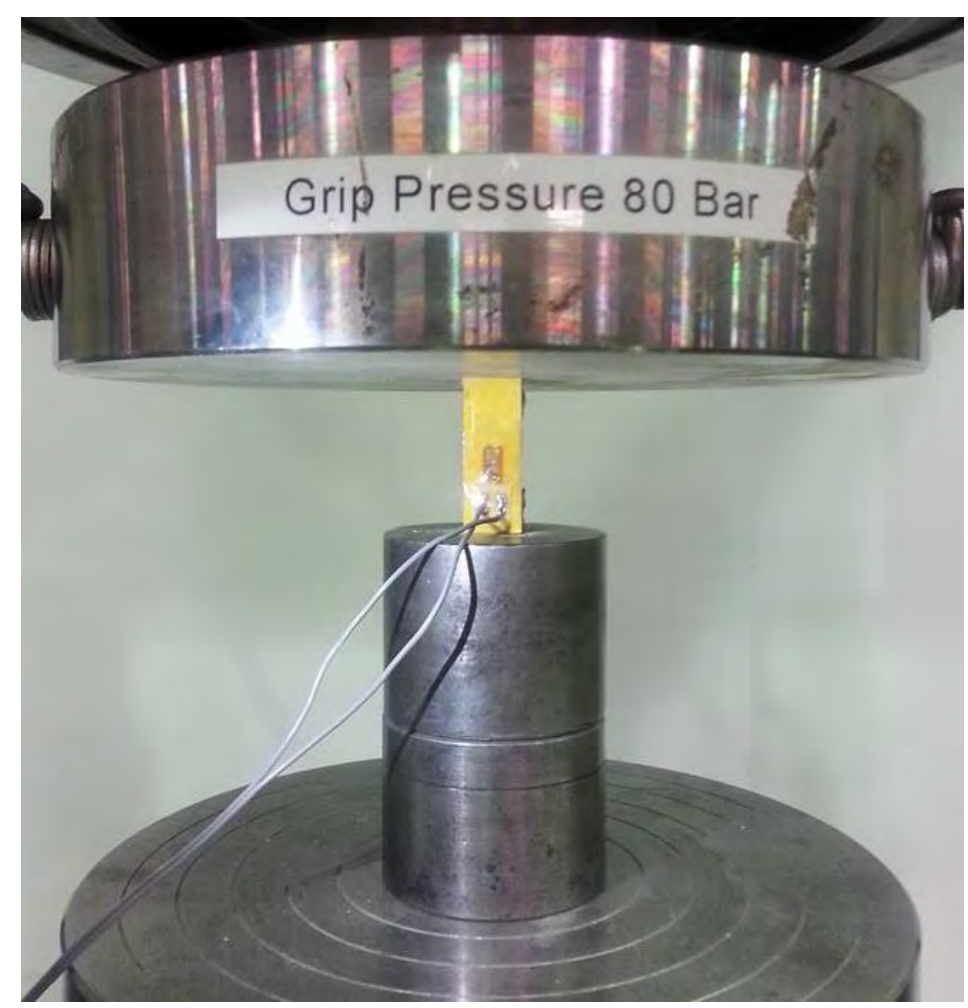

Fig. 2. Compression testing of pultruded GFRP sections 


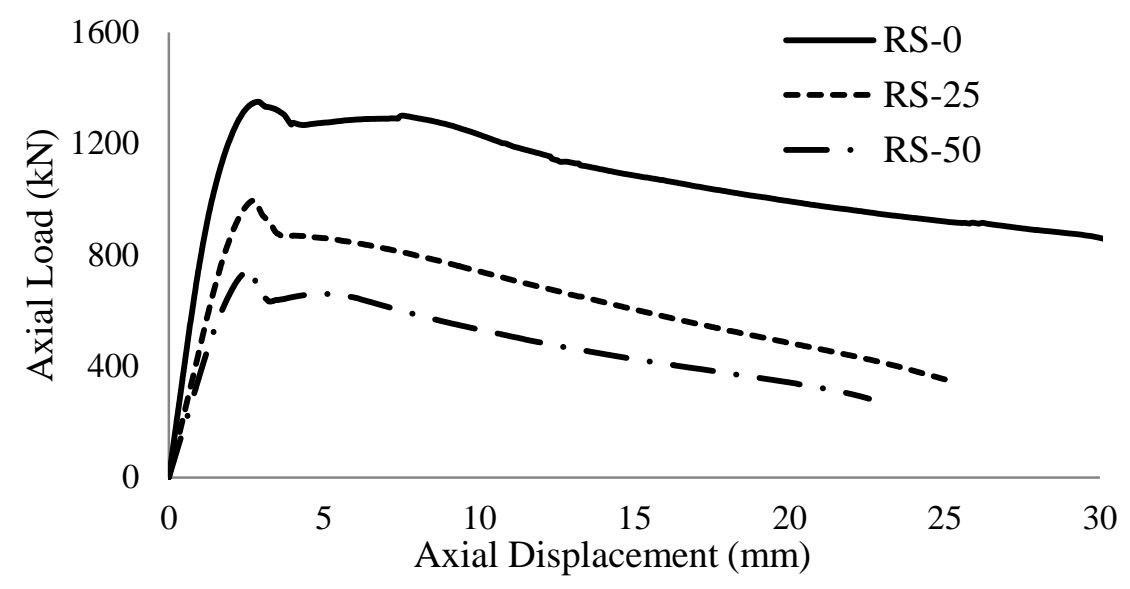

(a)

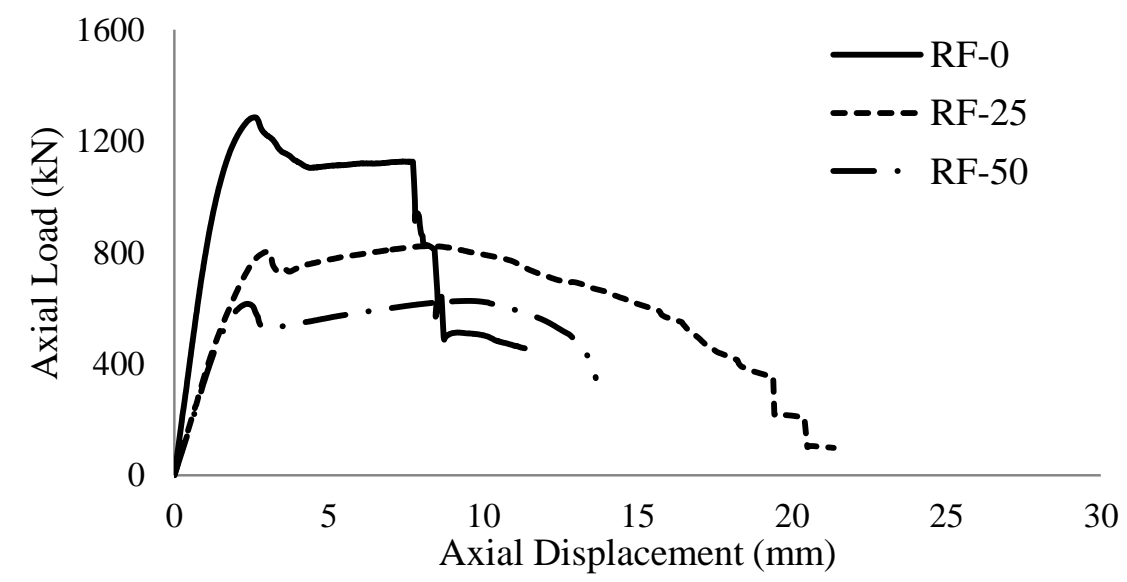

(c)

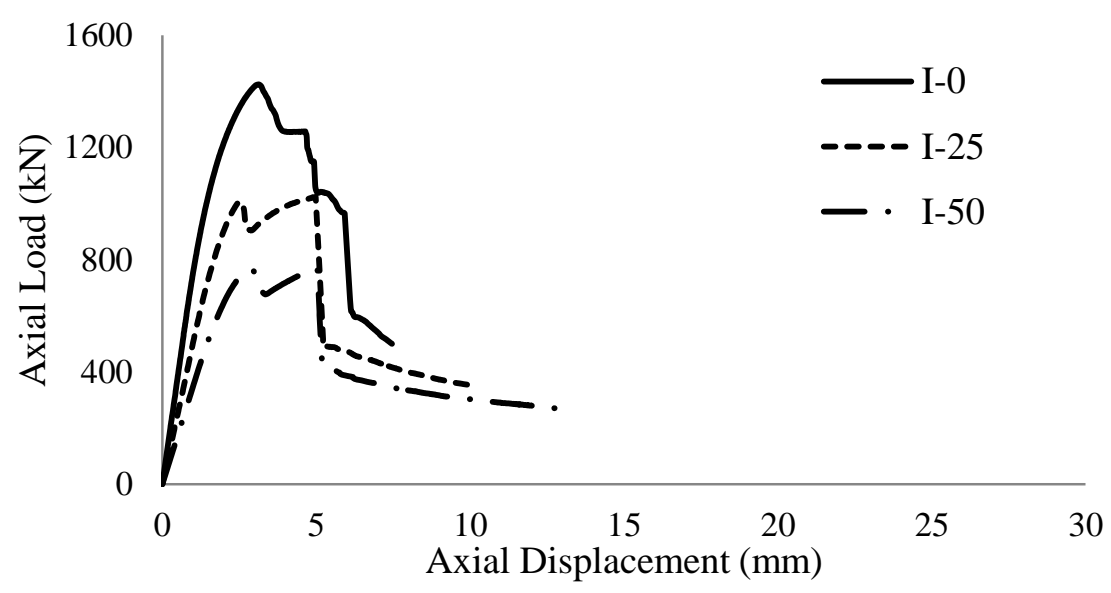

(b)

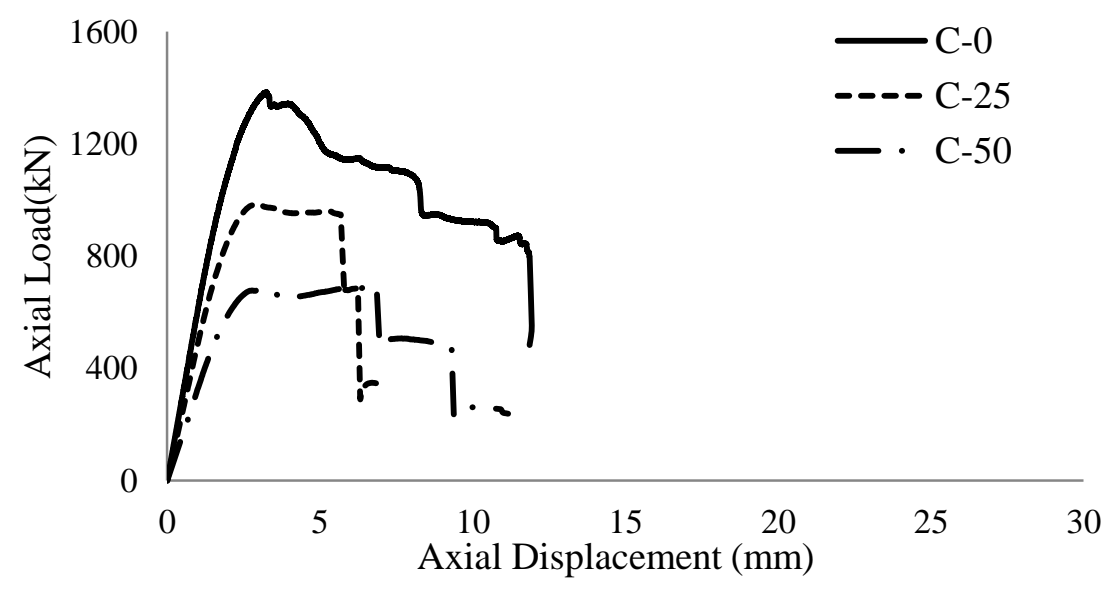

(d)

Fig. 3. Axial load-displacement relationships of column specimens with varying load eccentricities: (a) Group RS; (b) Group I; (c) Group RF; and (d) Group C 


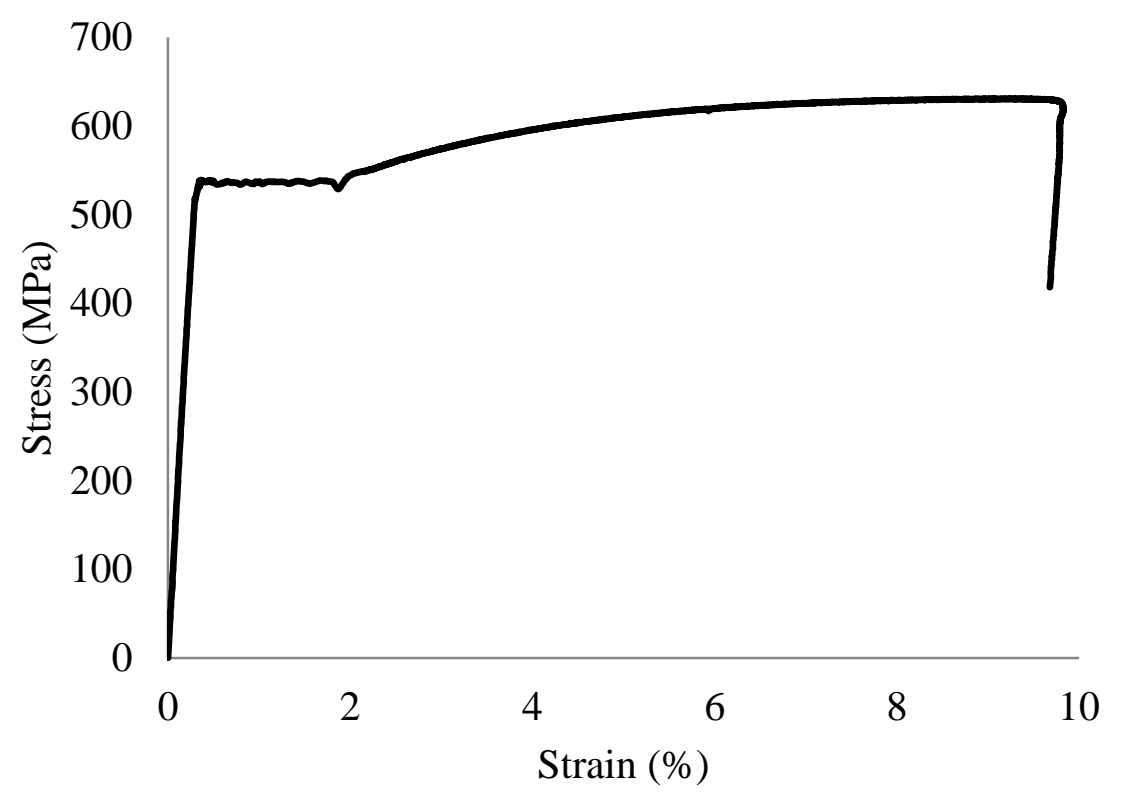

(a)

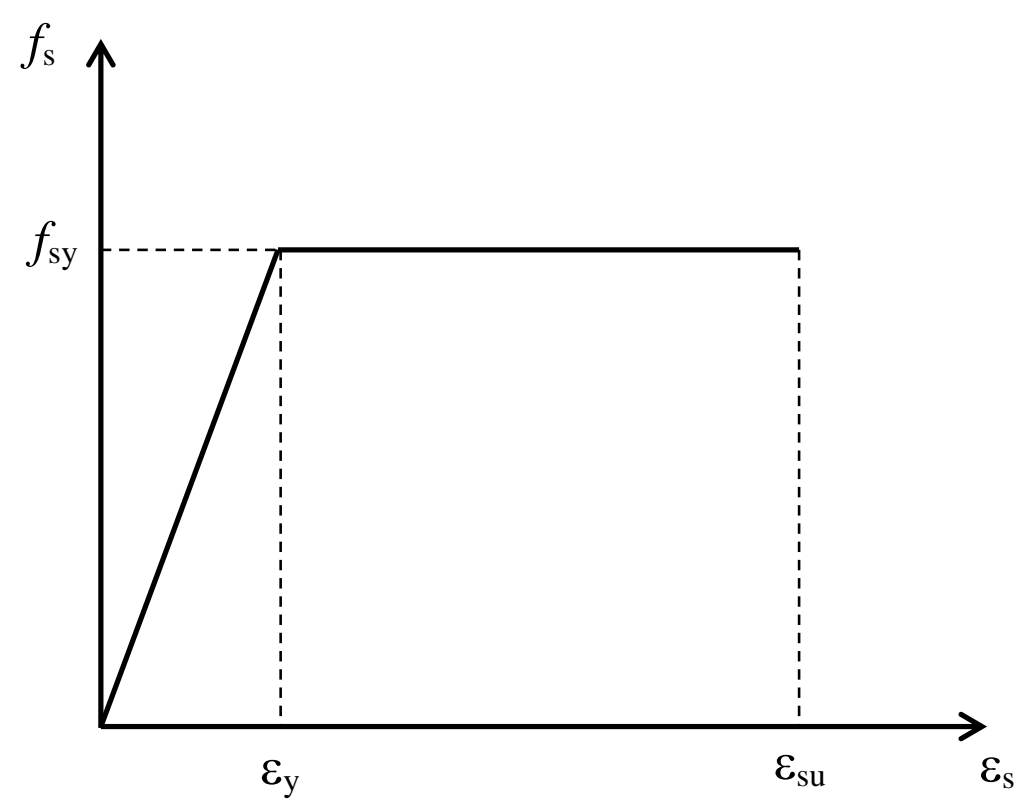

(b)

Fig. 4. Stress-Strain Relationships of N12 longitudinal steel bar:

(a) Experimental; and (b) Idealised 


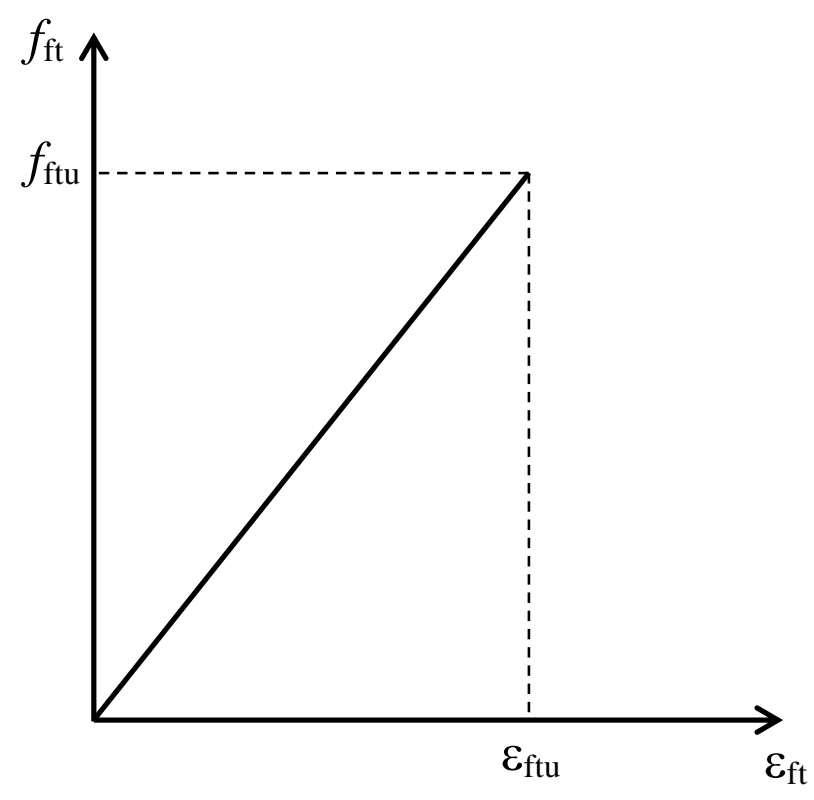

Fig. 5. Experimental and idealised stress-strain relationship of longitudinal GFRP bar 


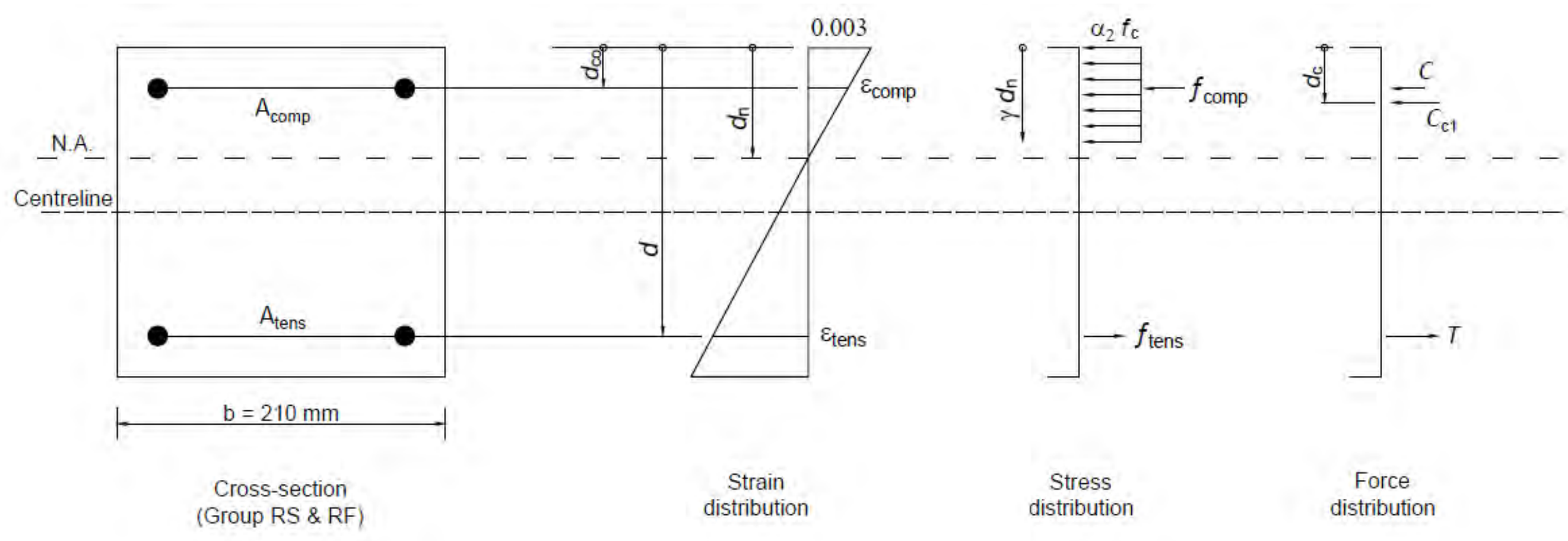

Fig. 6. Rectangular stress block method and force distribution of reinforcement for Group RS and RF specimens 


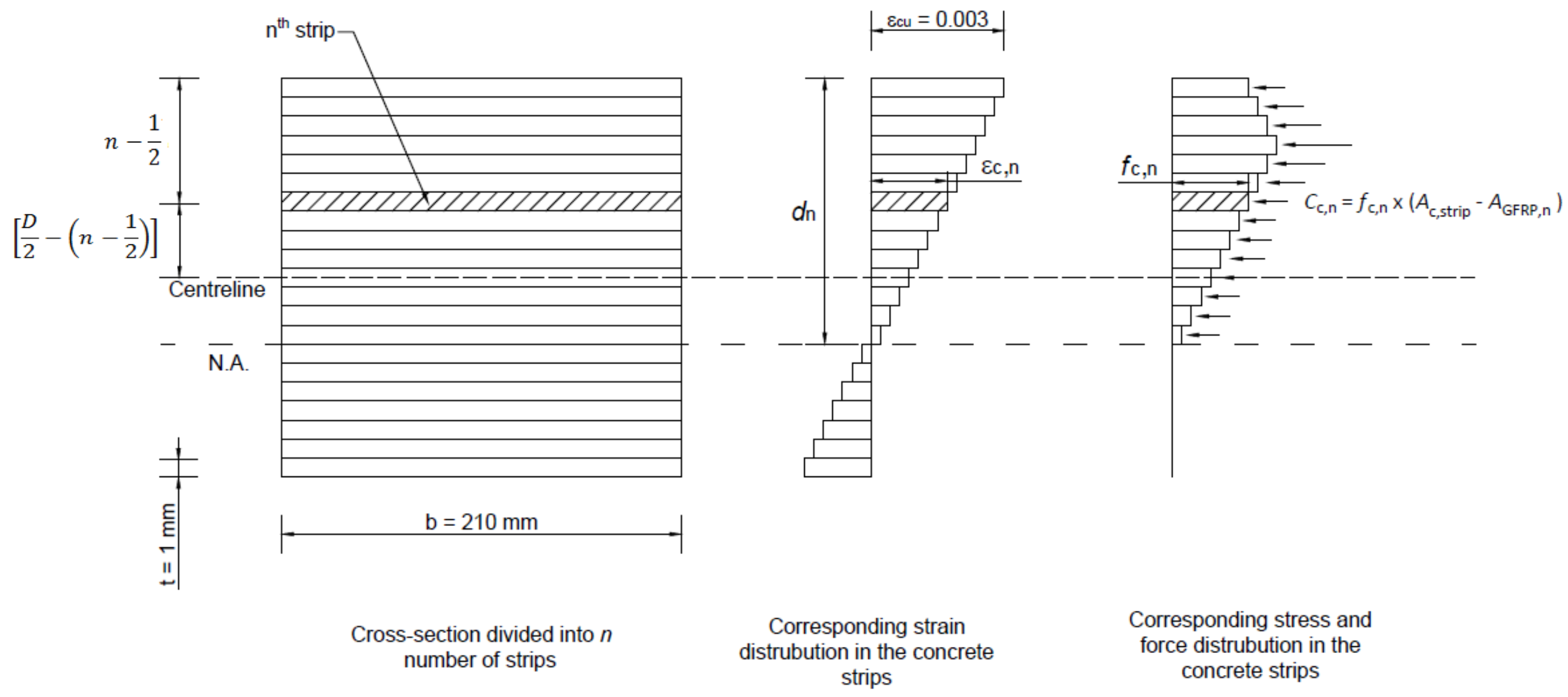

Fig. 7. Small strips method to determine the concrete compressive response 


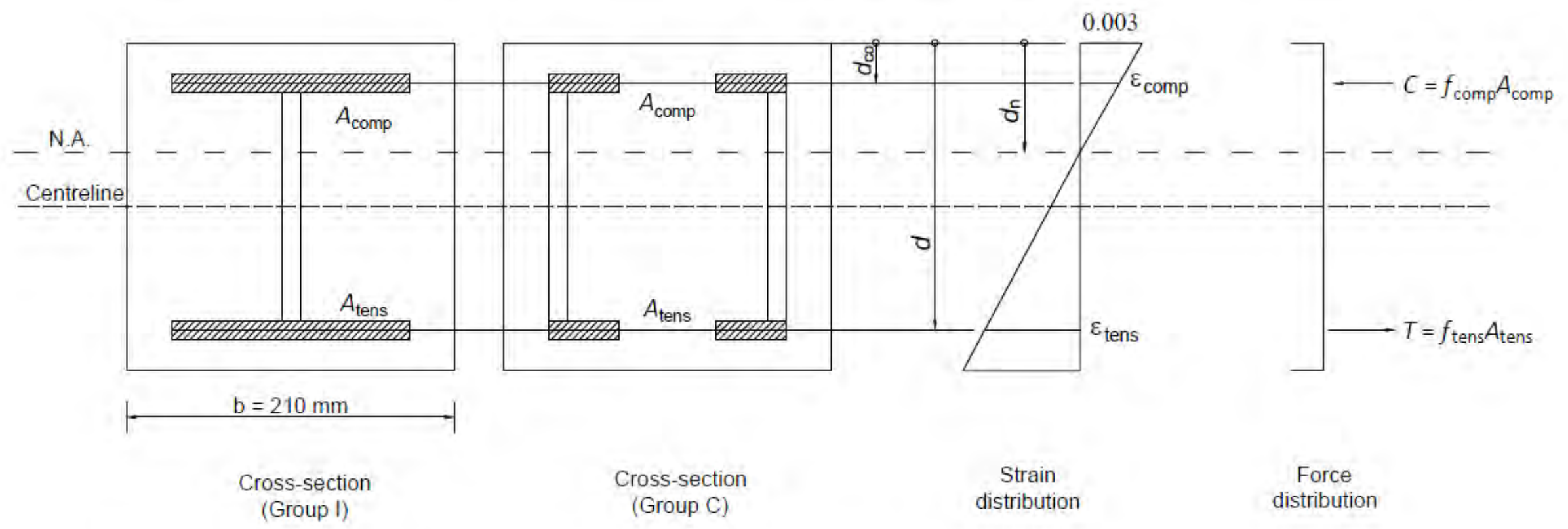

Notes: Concrete force distribution is calculated using the small strips method. Force contribution of the webs is neglected.

Fig. 8. Force distribution of specimens of Group I and C 


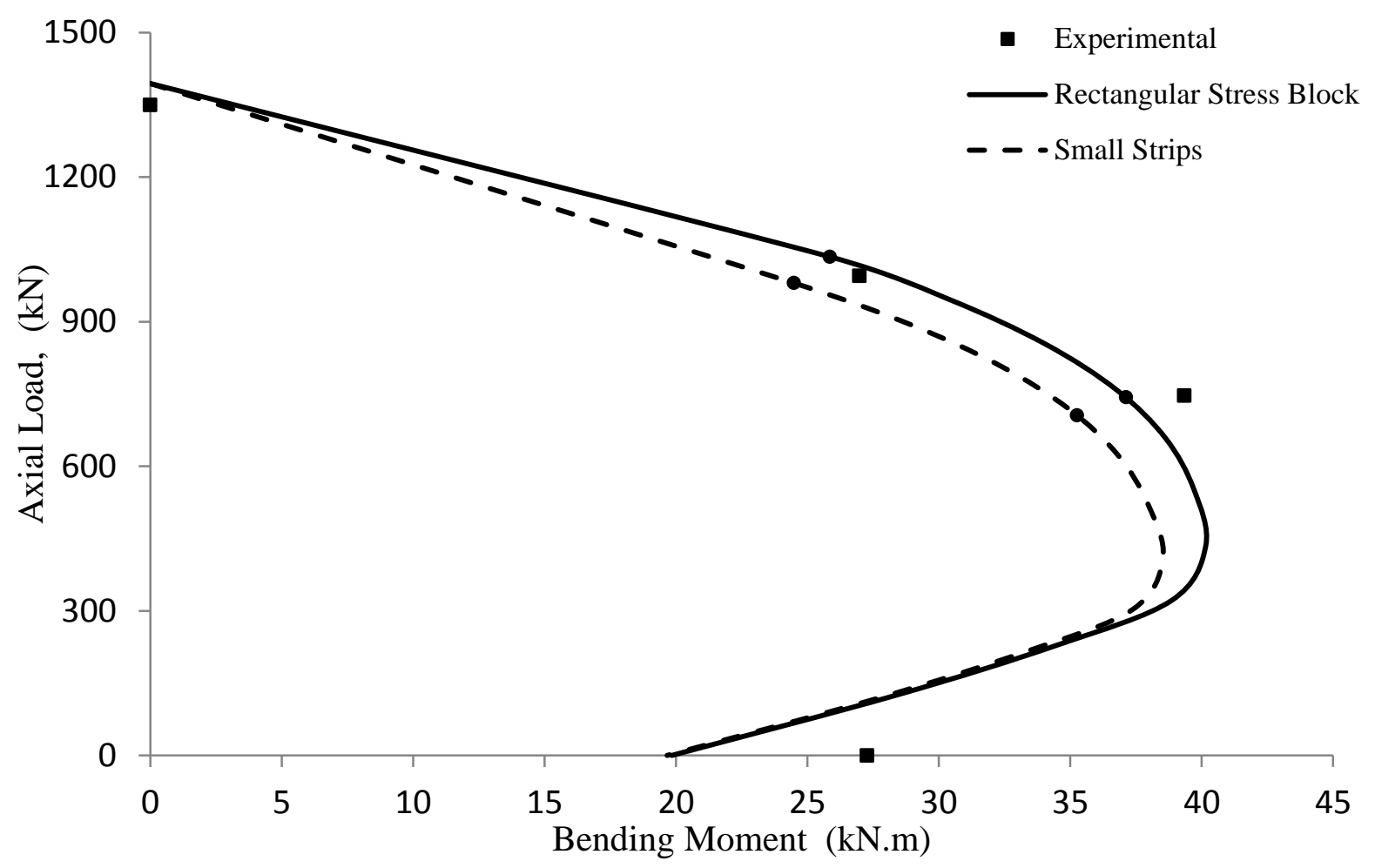

Fig. 9. Comparison of theoretical P-M diagrams and experimental results for Group RS specimens 


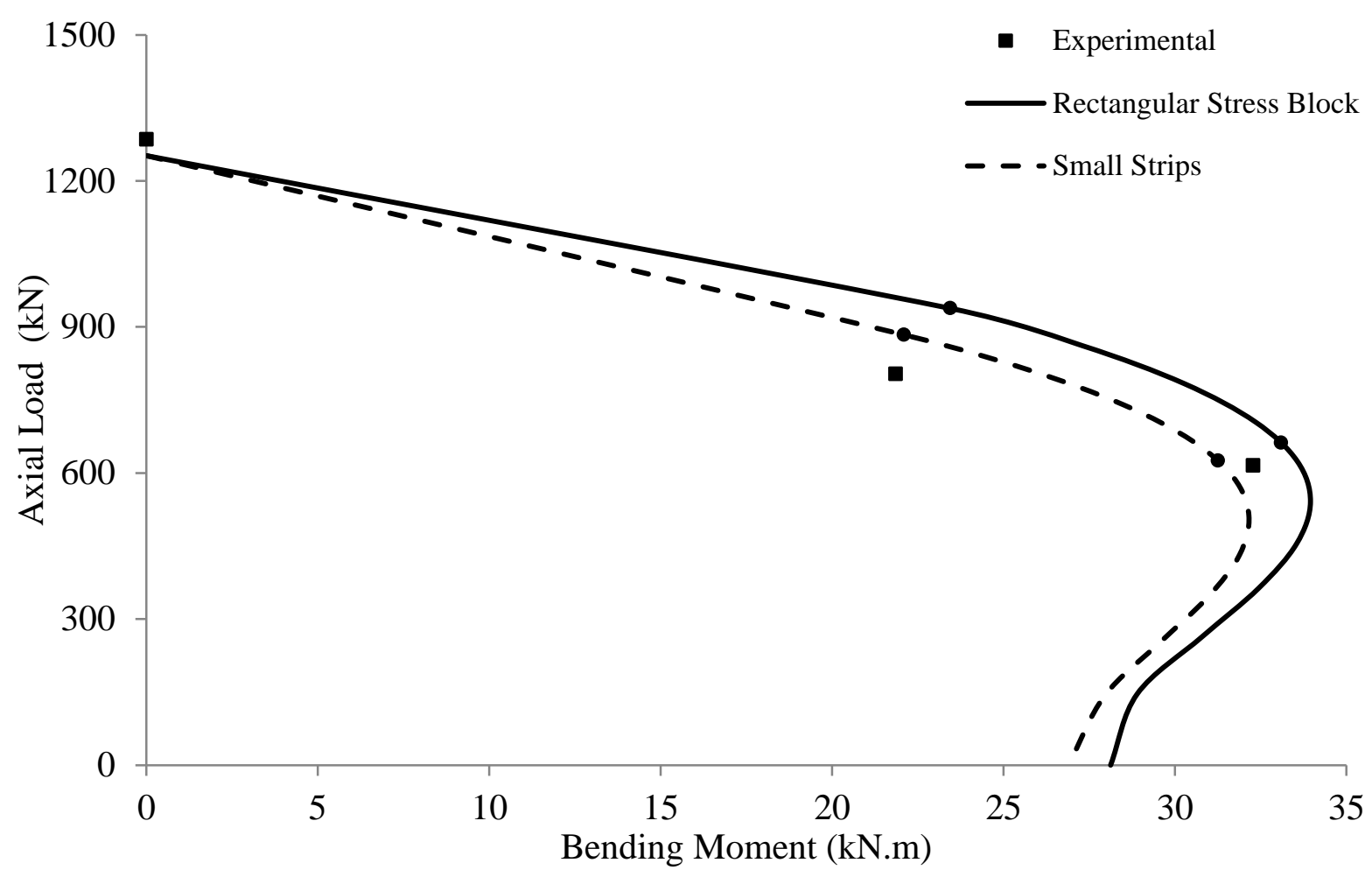

(a)

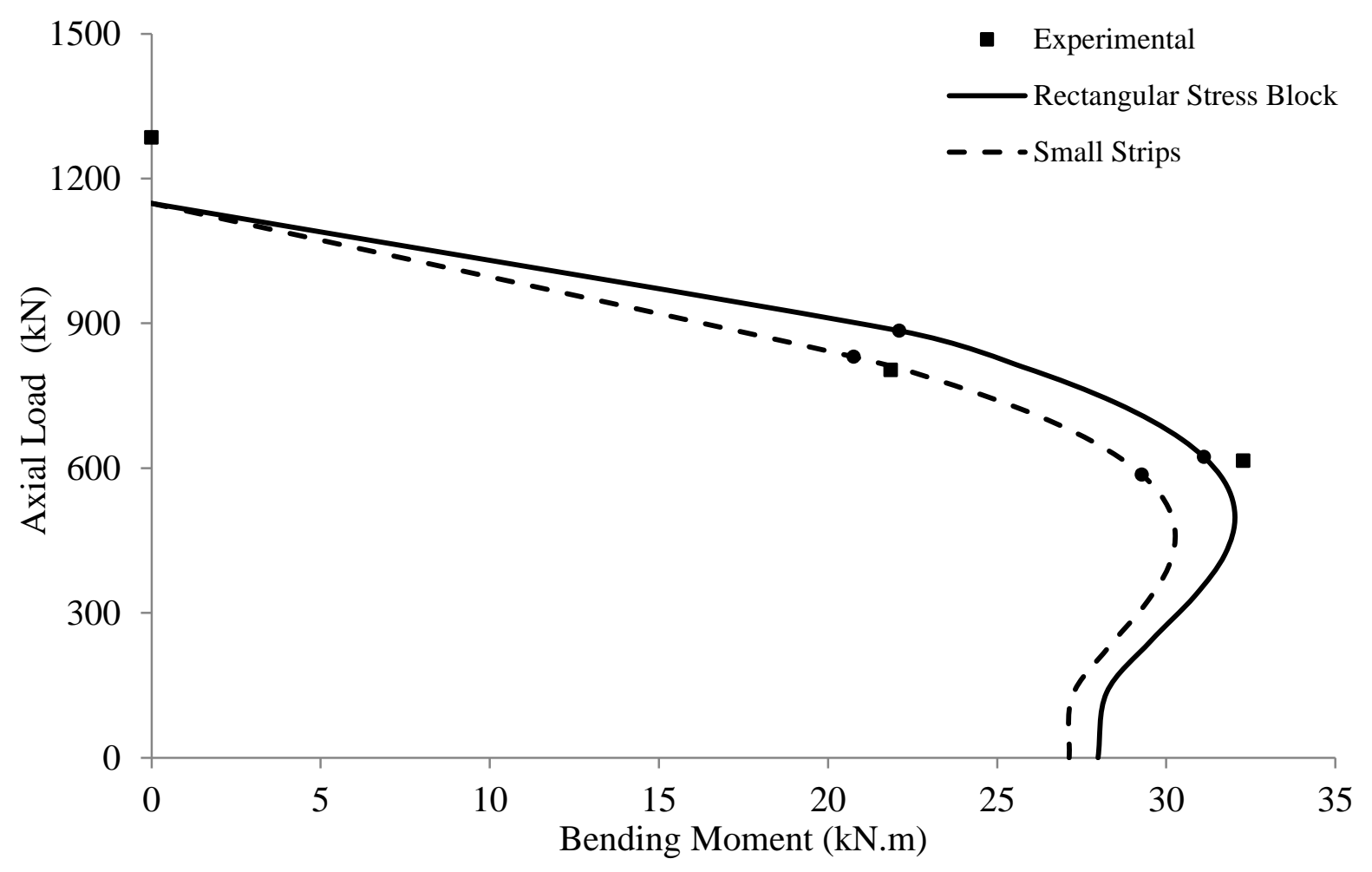

(b)

Fig. 10. Comparison of theoretical P-M diagrams and experimental results for Group RS specimens: (a) Compressive contribution of GFRP bars included $\left(\mathrm{E}_{\mathrm{fc}}=\mathrm{E}_{\mathrm{ft}}\right)$; and (b) Compressive contribution of GFRP bars ignored $\left(\mathrm{E}_{\mathrm{fc}}=0\right)$ 


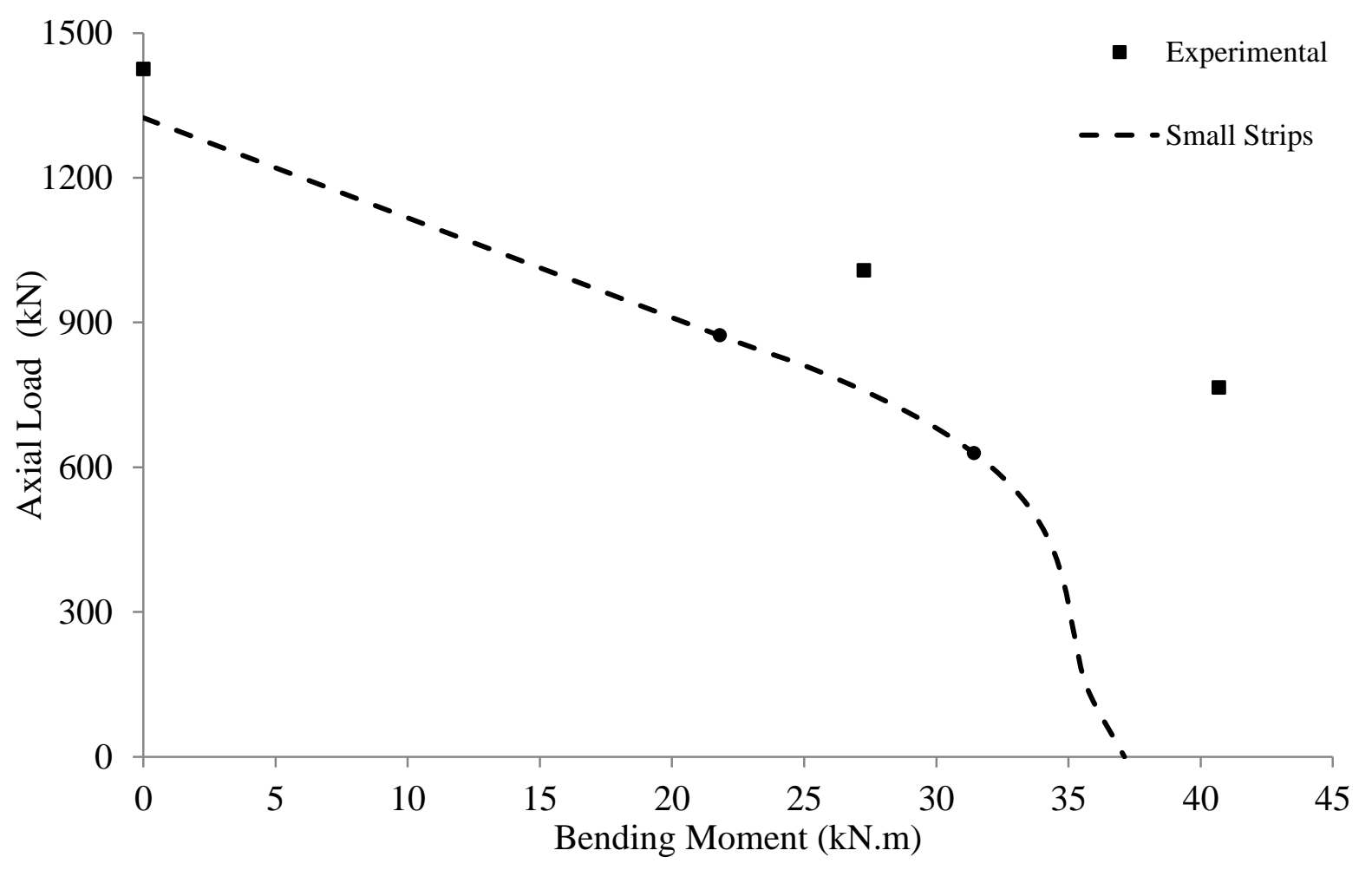

Fig. 11. Comparison of theoretical P-M diagrams and experimental results for Group I specimens 


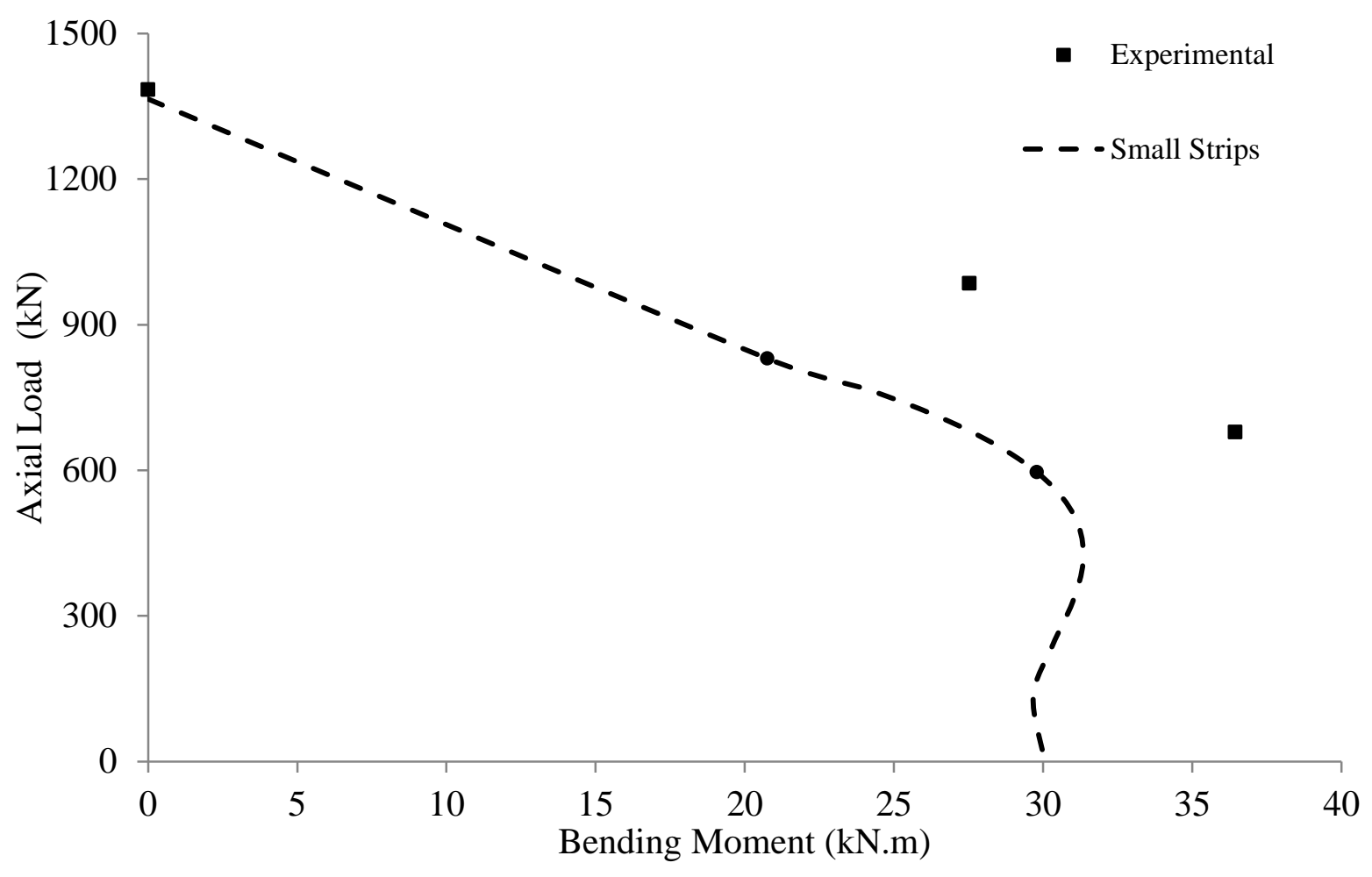

Fig. 12. Comparison of theoretical P-M diagrams and experimental results for Group C specimens 


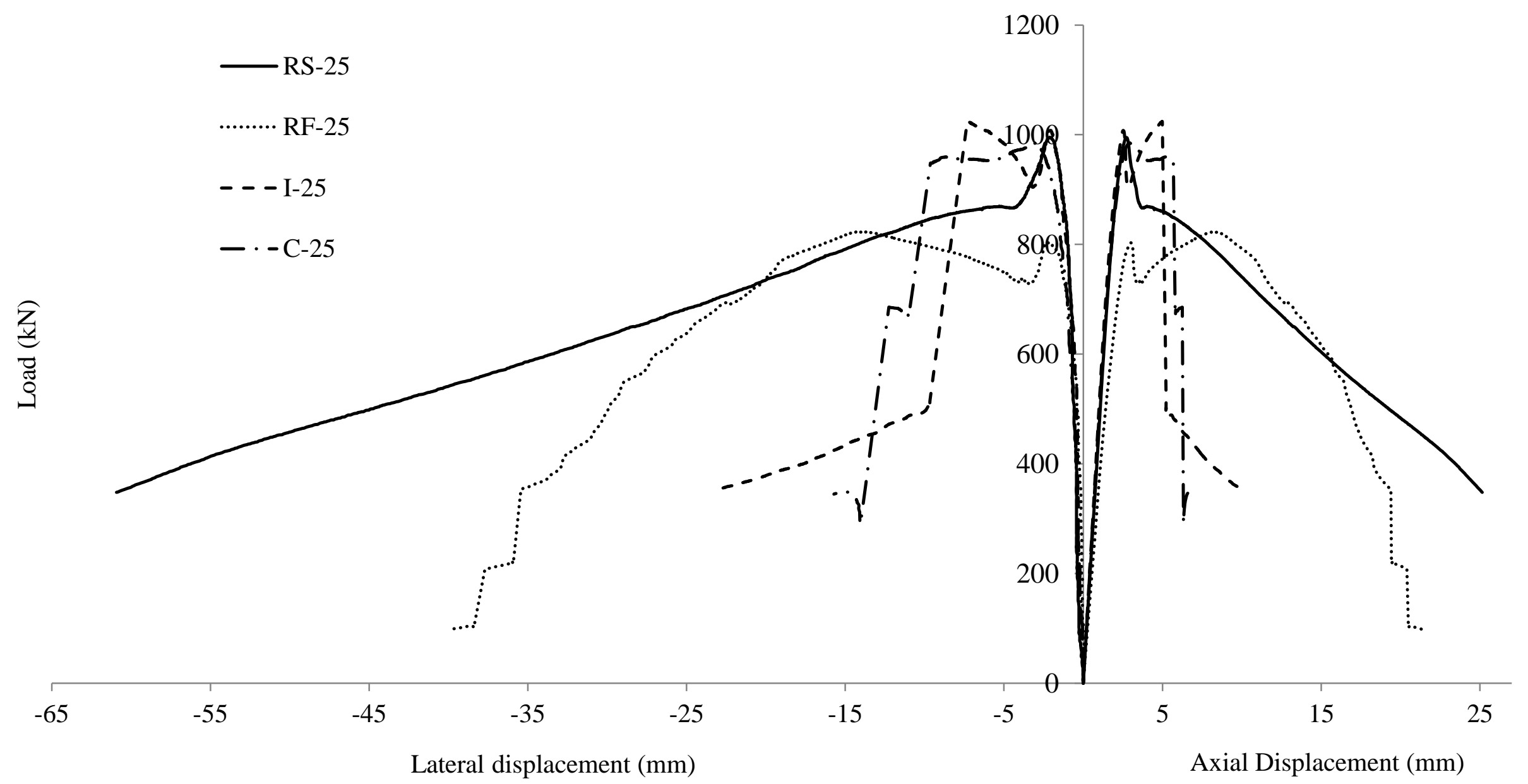

Fig. 13. Axial and lateral load-deflection curves of the $25 \mathrm{~mm}$ eccentrically loaded column specimens, e $=25 \mathrm{~mm}$ 


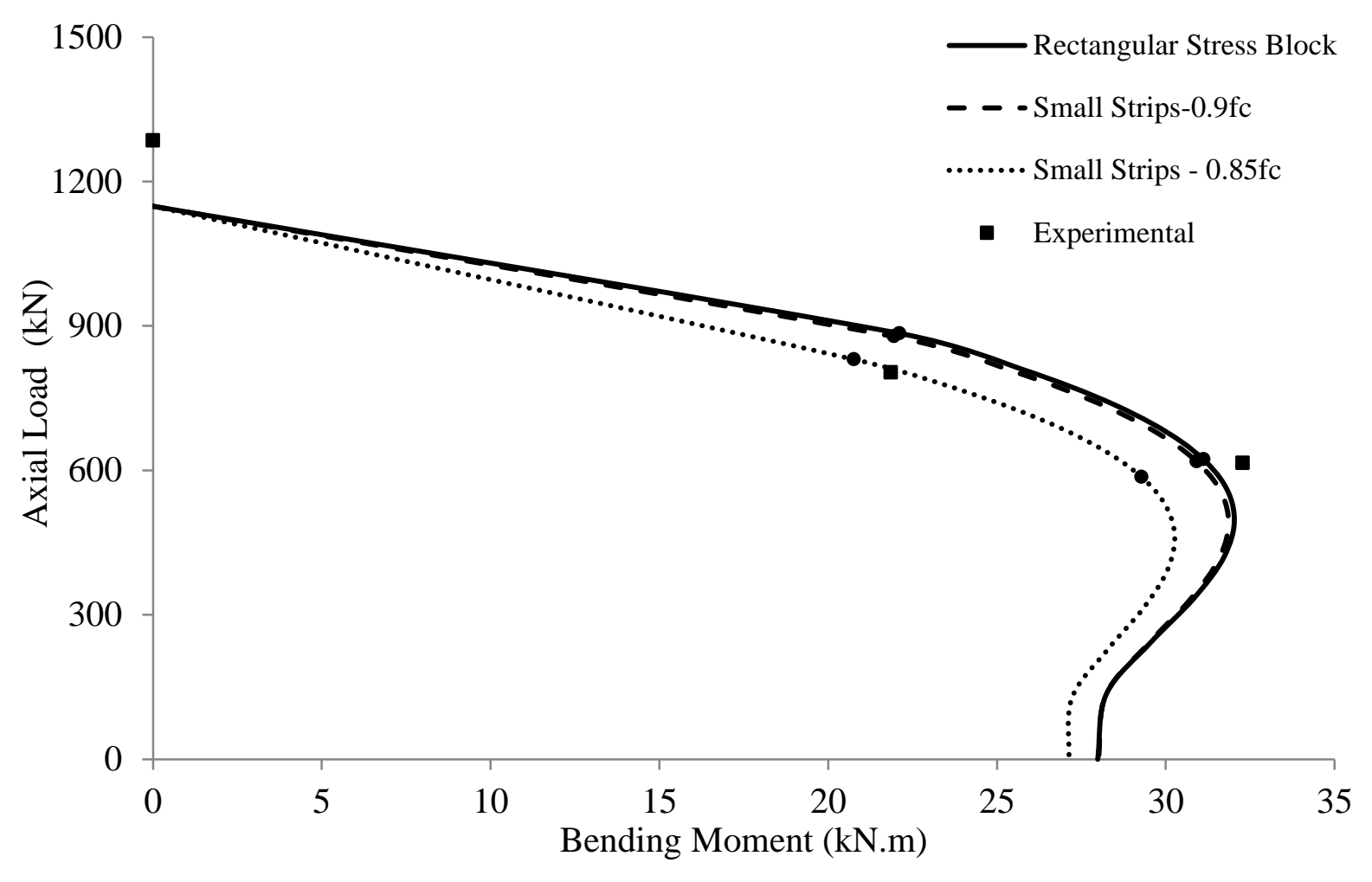

Fig. 14. Theoretical P-M diagrams of Group RF specimens when varying the maximum stress of concrete from $0.85 f_{\mathrm{c}}$ to $0.9 f_{\mathrm{c}}$ and assuming $E_{\mathrm{fc}}=0$ 


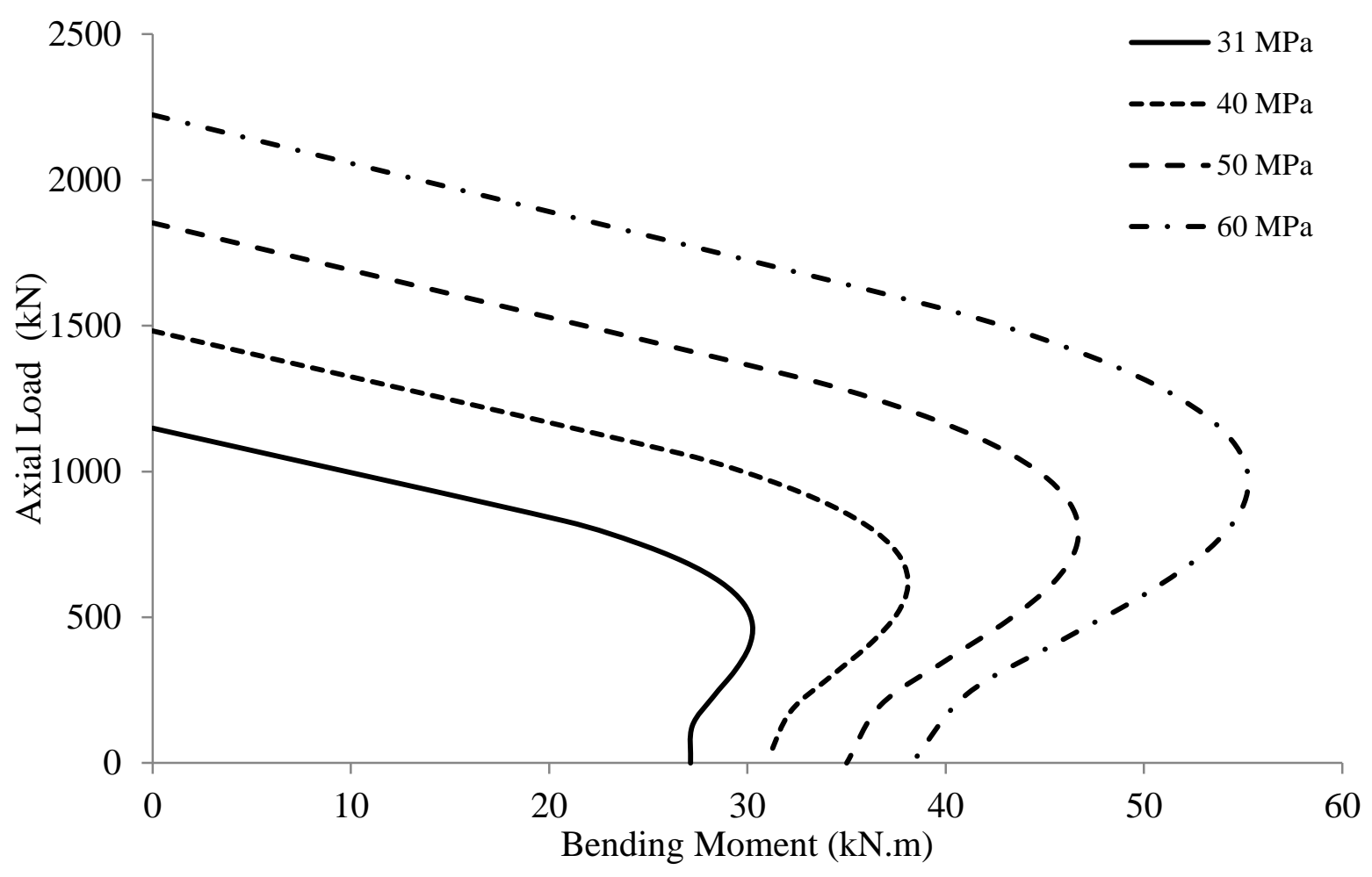

Fig. 15. Influence of concrete strength on P-M interaction diagrams for Specimens RF 


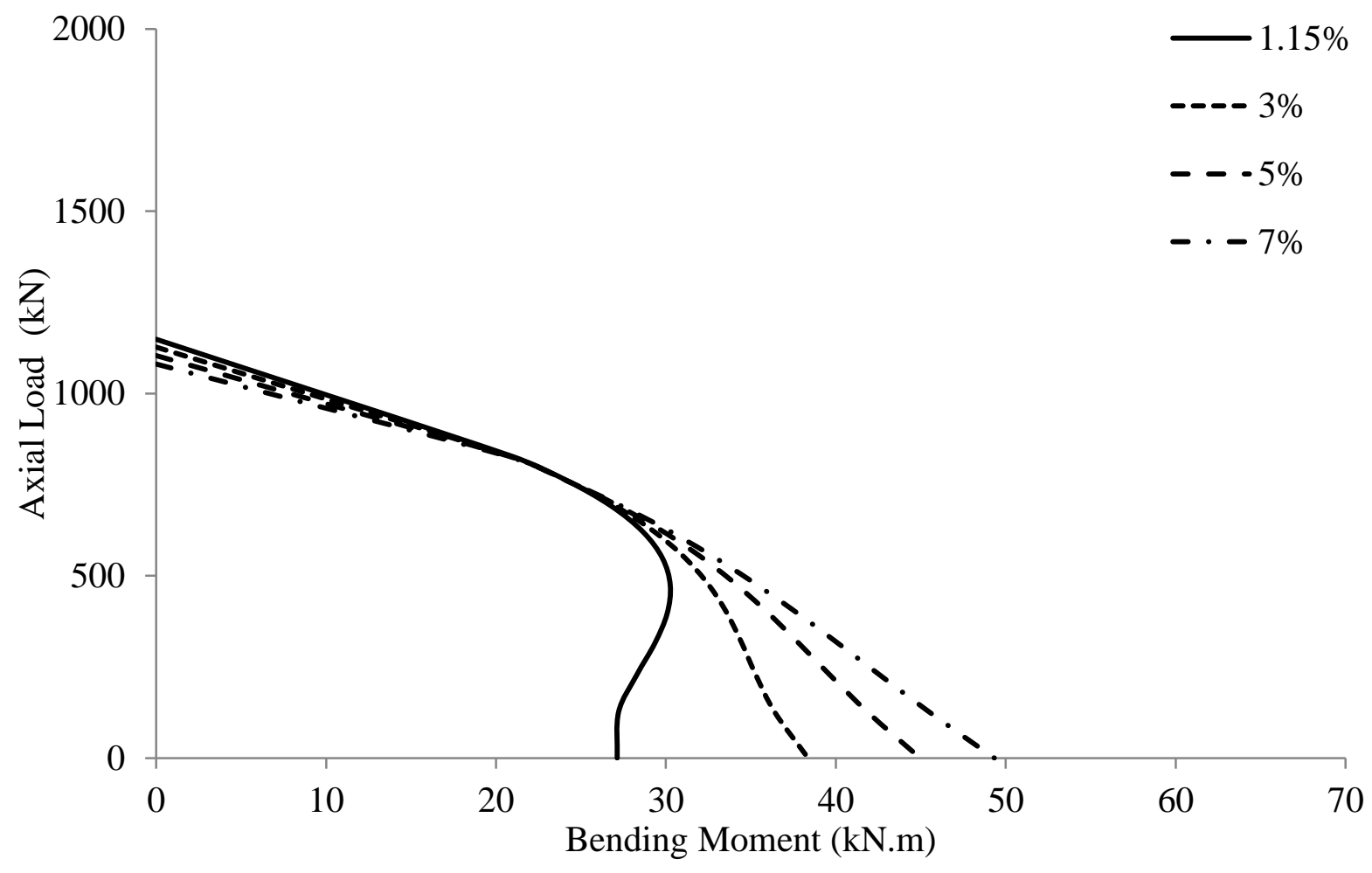

(a)

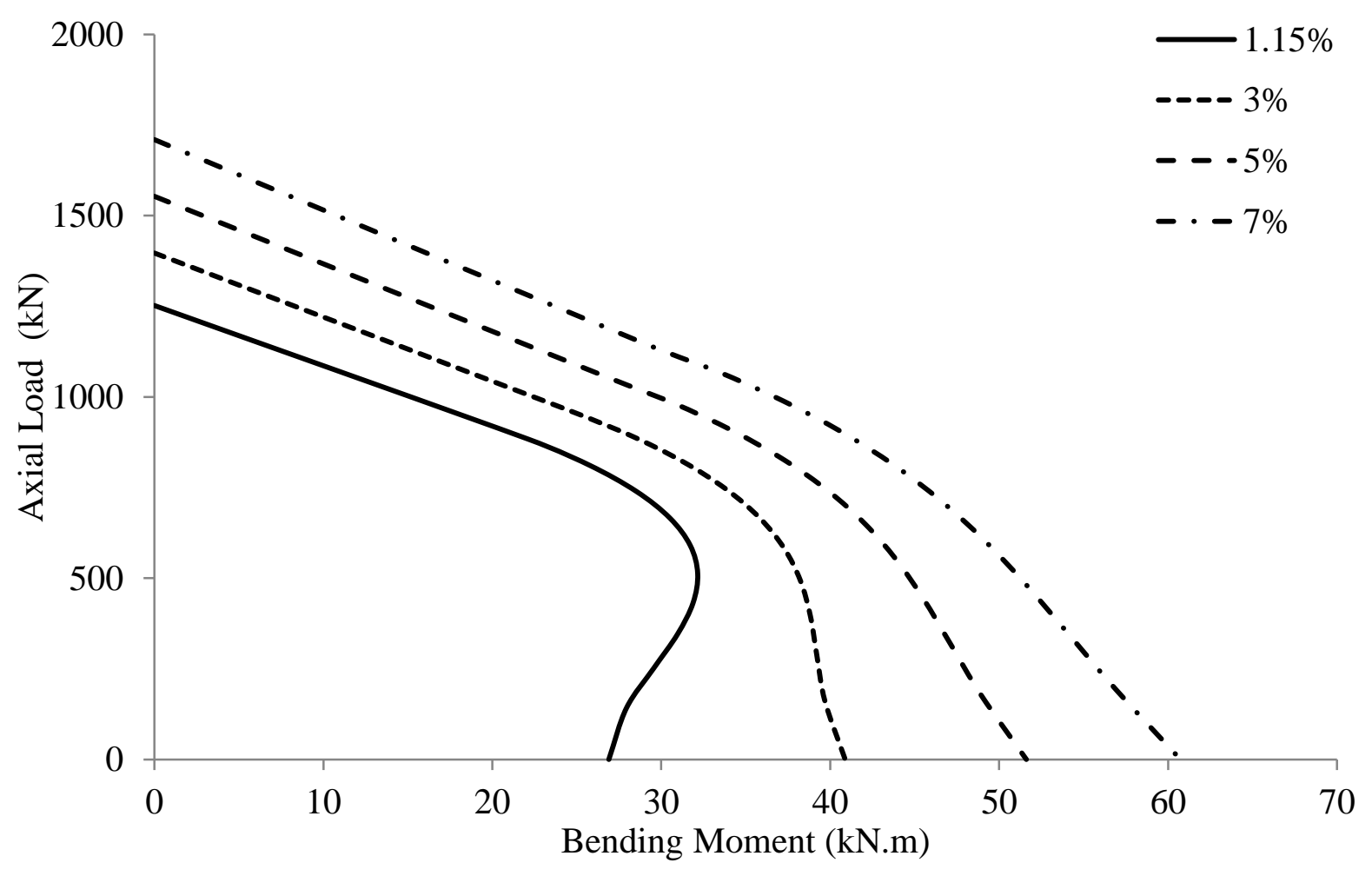

(b)

Fig. 16. Influence of longitudinal GFRP reinforcement ratio on P-M interaction diagrams:

(a) Compressive contribution of GFRP bars ignored $\left(\mathrm{E}_{\mathrm{fc}}=0\right)$; and (b) Compressive contribution of GFRP bars included $\left(\mathrm{E}_{\mathrm{fc}}=\mathrm{E}_{\mathrm{ft}}\right)$ 